Vol. 70, N. ${ }^{\circ}$ III (mayo 20I8), II3-I5I

\title{
EL CAPITAL
}

\section{CRÍTICA DE LA ECONOMÍA POLÍTICA}

\author{
KARL MARX
}

LIBRO PRIMERO

EL PROCESO DE PRODUCCIÓN DEL CAPITAL

\author{
SECCIÓN PRIMERA \\ MERCANCÍA Y DINERO
}

\section{CAPÍTULO PRIMERO}

LA MERCANCÍA

\begin{abstract}
NOTA EDITORIAL. Con motivo de esta edición especial de aniversario sobre el gran pensador de Tréveris una de las tareas imprescindibles es, sin duda, el rescate — además- del trabajo de sus muchos continuadores que (re)pensaron a K. Marx desde sus múltiples dimensiones, espacios y críticas. Uno de estos autores más cercano a nosotros y destacado a nivel latinoamericano es, indiscutiblemente, el profesor Bolívar Echeverría (1941-2010). En este contexto, y con la pretensión de rescatar la memoria histórica de su gran obra El capital, pero a través de los ojos y el pensamiento de Bolívar Echeverría, a continuación tenemos el honor de republicar una verdadera «joya» del pensamiento marxista latinoamericano: la traducción del Capítulo I: La mercancía, Sección I del Libro i que, en principio, fue publicada en la Revista Anales n. 354 (1976) de la Universidad Central del Ecuador y que, ahora, gracias a la generosa autorización de la profesora Raquel Serur podemos (re)disfrutarla. [Se han respetado las características tipográficas de la época, excepto negrillas y notas a pie de página, éstas han ido al final. N. del E.].
\end{abstract}

\section{Nueva traducción}

\section{Bolívar Echeverría}

[Las variantes que se introducen aquí son las principales de las que aparecen exclusivamente en la versión francesa. No se tienen en cuenta - con la sola excepción de los subrayados- las que distinguen al texto de la primera edición; tampoco, por tanto, aquellas de entre éstas que se mantienen en la edición francesa]. 


\section{CAPÍTULO PRIMERO}

\section{LOS DOS FACTORES DE LA MERCANCÍA:}

VALOR DE USO Y VALOR (SUBSTANCIA DEL VALOR, MAGNITUD DEL VALOR)

La riqueza de las sociedades en las que domina el modo de producción capitalista se presentan como un «inmenso almacenamiento de mercancías» ${ }^{1}$ y cada mercancía como su forma elemental. De ahí que nuestra investigación comience por el análisis de la mercancía.

La mercancía es, ante todo, un objeto externo, una cosa que por sus cualidades satisface algún tipo de necesidades humanas. La naturaleza de estas necesidades, el que broten por ejemplo del estómago o de la fantasía, no modifica en nada este hecho. ${ }^{2}$ Tampoco se trata de considerar cómo la cosa satisface las necesidades humanas, si directamente como medio de vida, es decir como objeto de disfrute, o indirectamente, como medio de producción.

Todo objeto útil, el hierro, el papel, etc., debe considerarse desde un doble punto de vista, según su cualidad y según su cantidad. Cada uno de estos objetos es un todo de muchas cualidades y puede, por tanto, ser útil en diversos aspectos. El descubrimiento de estos diversos aspectos y, por tanto, de los diversos modos como pueden usarse las cosas es obra de la historia. ${ }^{3}$ Y lo mismo la invención de las medidas sociales para la cantidad de las cosas útiles. La diversidad de las medidas de las mercancías brota, en parte, de la distinta naturaleza de los objetos que se trata de medir $\mathrm{y}$, en parte, de un acto convencional.

La utilidad de un objeto lo constituye como valor de uso. ${ }^{4}$ Pero esta utilidad no flota en el aire. Se halla condicionada por las cualidades del cuerpo de la mercancía y no puede existir sin él. El cuerpo mismo de la mercancía, por ejemplo, el hierro, el trigo, el diamante, etc., es, por tanto, un valor de uso o un bien. Y este carácter que posee no de-pende de la cantidad mayor o menor del trabajo que le cueste al hombre la apropiación de sus cualidades de uso. Cuando consideramos los valores de uso, presuponemos siempre su determinabilidad cuantitativa: una docena de relojes, una vara de lienzo, una tonelada de hierro, etc. Los valores de uso de las mercancías ofrecen el material para una disciplina especial, la teoría de los bienes [Warenkunde]. ${ }^{5}$ El contenido material de la riqueza, cualquiera que sea su forma social, está compuesto de valores de uso. Y en la forma de sociedad estudiada por nosotros estos valores de uso son, al mismo tiempo, los portadores materiales del valor de cambio.

El valor de cambio se presenta ante todo como la relación cuantitativa o proporción en que valores de uso de una clase se cambian por valores de uso de otra, ${ }^{6}$ proporción que cambia constantemente en el tiempo y en el espacio. Esto hace que el valor de cambio parezca ser algo fortuito y puramente relativo y que, por tanto, el hablar de un valor de cambio inmanente, inherente a la mercancía (valeur intrinseque) parezca implicar una contradictio in abjecto [contradicción en el adjetivo].7 Pero fijémonos más de cerca en la cosa.

Una cierta mercancía, por ejemplo una arroba de trigo, se cambia por $\mathrm{x}$ betún, y seda, $\mathrm{z}$ oro, etc., en una palabra, por otras mercancías en las más diversas proporciones. Esto quiere decir que el trigo tiene múltiples valores de cambio, y no uno solo. Pero, como $\mathrm{x}$ betún lo mismo que y seda, $\mathrm{z}$ oro, etc., es el valor de cambio de una arroba de trigo, tenemos que $\mathrm{x}$ betún, y seda, $\mathrm{z}$ oro, etc., deben ser substituibles entre sí o, lo que es lo mismo, valores de cambio de igual magnitud. De donde, por tanto, se sigue, primero, que los diversos valores de cambio vigentes de 
la misma mercancía expresan algo igual. Y segundo, que el valor de cambio sólo puede ser el modo de expresión, la «forma de manifestación» de un contenido diferenciable de él.

Tomemos ahora dos mercancías, por ejemplo trigo y hierro. Cualquiera que sea la pro-porción en que se intercambien, siempre podrá expresarse por medio de una ecuación, en la que una cantidad dada de trigo equivalga a una determinada cantidad de hierro, por ejemplo, una arroba de trigo = a quintales de hierro. ¿Qué nos dice esta ecuación? Que en dos cosas distintas existe un algo común de idéntica magnitud, lo mismo en una arroba de trigo que en a quintales de hierro. Ambas cosas son, por tanto, iguales a una tercera, que no es propiamente ni la una ni la otra. Por lo tanto, cada una de las dos, en cuanto valor de cambio, debe ser reductible a esta tercera.

Un ejemplo geométrico simple aclarará lo que decimos. Para determinar y comparar el área de todas las figuras rectilíneas se les reduce a triángulos. Y, a su vez, el triángulo es reducido a una expresión completamente distinta de su figura visible, a la mitad del producto de su base por su altura. Pues bien, también a los valores de cambio de las mercancías hay que reducirlos a un algo común del cual cada uno de ellos representa un más o un menos.

Este algo común no puede ser una propiedad geométrica, física, química u otra pro-piedad natural cualquiera de las mercancías. Estas cualidades de su cuerpo sólo interesan en cuanto hacen de ellas cosas útiles, es decir, valores de uso. Y es precisamente la abstracción de sus valores de uso lo que evidentemente caracteriza la relación proporcional de intercambio entre las mercancías. Dentro de ella, tanto da un valor de uso como otro, siempre y cuando se encuentre en una proporción adecuada. $\mathrm{O}$, como dice el viejo Barbon: «Una clase de cosas es tan buena como otra, si el valor de cambio de la una es igual al de la otra. Entre cosas que tienen un valor de cambio igual no existe diferencia o diferenciabilidad alguna». ${ }^{8}$ Como valores de uso, las cosas son, ante todo, de distinta cualidad; como valores de cambio sólo pueden ser de distinta cantidad, y no encierran por tanto ni un átomo de valor de uso.

Ahora bien, si hacemos caso omiso del valor de uso de los cuerpos de las mercancías a éstos sólo les queda una cualidad, la de ser productos del trabajo. Pero, con ello, también el producto del trabajo se transforma en nuestras manos. Al hacer abstracción de su valor de uso, abstraemos también los elementos corporales y las formas que hacen de él un valor de uso. Deja de ser una mesa, una casa, una hilaza o cualquier otra cosa útil. Se borran todas sus cualidades sensibles. Deja de ser, asimismo el producto del trabajo del carpintero, del trabajo del agricultor, del trabajo del hilandero o de cualquier trabajo productivo específico. Junto con el carácter útil de los productos del trabajo, desaparece el carácter útil de los trabajos que se manifiestan en ellos y desaparecen también, por tanto, las distintas formas concretas de estos trabajos, que ya no se distinguirán unos de otros, sino que quedarán todos ellos reducidos a trabajo humano igual, a trabajo humano abstracto.

Detengámonos a considerar lo que queda de los productos del trabajo. El único residuo de todos ellos es una misma espectral objetividad, una simple condensación de trabajo humano indistinto, es decir, una condensación del gasto de fuerza de trabajo humana, en la que no está tomada en consideración la forma de este gasto. Estos objetos sólo representan el hecho de que en su producción se ha gastado fuerza de trabajo humana, se ha acumulado trabajo humano. Como cristalización de esta sustancia social común a ellos, son valores, son los valores de las mercancías. 
Ya en la proporción de intercambio de las mercancías, su valor de cambio se nos aparecía como algo completamente independiente de sus valores de uso. Si ahora se hace realmente abstracción del valor de uso de los productos del trabajo, se obtendrá su valor, tal como acaba de ser determinado. Lo común, lo que se representa en la proporción de intercambio de la mercancía, es, por tanto, su valor. El curso de nuestra investigación, nos traerá nuevamente ante el valor de cambio como el necesario modo de expresión o forma de manifestación del valor; sin embargo, primero considerémoslo independientemente de esta forma.

Sabemos, pues, que un valor de uso o un bien sólo tiene un valor por cuanto que en él se objetiva o materializa trabajo humano en abstracto. Pero, ¿cómo medir la magnitud de su valor? Por la cantidad de "sustancia creadora de valor», esto es de trabajo, que en él se contiene. A su vez, la cantidad de trabajo se mide por el tiempo que dura y este tiempo trabajo, por su parte posee su medida en determinadas fracciones de tiempo, como horas, días, etc.

Podría parecer, a primera vista, que si el valor de una mercancía se determina por la cantidad de trabajo empleada en producirla, cuanto más indolente o más torpe sea un individuo, mayor valor tendrá s mercancía, puesto que necesitará más tiempo para elaborarla. Sin embargo, el trabajo que constituye la sustancia de los valores es trabajo humano igual, es gasto de la misma fuerza de trabajo humano. La fuerza total de trabajo de la sociedad que se objetiva en los valores del mundo de las mercancías entra aquí como una y la misma fuerza humana de trabajo, aunque esté formada por innumerables fuerzas de trabajo individuales. Cada una de estas fuerzas individuales de trabajo es igual a cualquier otra, siempre y cuando que posea el carácter de una fuerza de trabajo social media y actué como tal, es decir, que sólo requiera para producir una mercancía el promedio de tiempo de trabajo o el tiempo de trabajo socialmente necesario. Tiempo de trabajo socialmente necesario es el que se requiere para hacer [darstellen] un valor de uso cualquiera en las condiciones de producción normales, socialmente dadas, y con el grado social medio de destreza e intensidad del trabajo. Así, por ejemplo, después de la introducción del telar a vapor en Inglaterra, bastaba aproximadamente con la mitad del trabajo que antes para tejer una determinada cantidad de hilaza. El tejedor manual inglés seguía necesitando, por supuesto, el mismo trabajo que antes para conseguir el mismo resultado, pero ahora el producto de su hora individual de trabajo sólo representaba media hora de trabajo social y había perdido, por tanto, la mitad de su valor anterior.

Por consiguiente, lo que determina la magnitud de valor de un bien sólo es la cantidad de trabajo socialmente necesario o el tiempo socialmente necesario para producirlo. ${ }^{9}$ Aquí, la mercancía singular vale exclusivamente como ejemplar medio de su especie. ${ }^{10}$ Mercancías que contienen cantidades iguales de trabajo o que pueden producirse en un tiempo de trabajo igual tienen, por tanto, la misma magnitud de valor. El valor de una mercancía es al valor de otra como el tiempo de trabajo necesario para la producción de la una es al tiempo de trabajo necesario para la producción de la otra. «En cuanto valores, todas las mercancías son solamente determinadas cantidades de trabajo cuajado». ${ }^{11}$

Así pues, si el tiempo de trabajo necesario para la producción de una mercancía permaneciera constante, la magnitud de su valor permanecería también constante. Pero el tiempo de trabajo necesario varía al variar la productividad del trabajo. La capacidad productiva del trabajo depende de una serie de factores, entre otros del grado medio de destreza del obrero, de 
nivel de desarrollo de la ciencia y de la posibilidad de su empleo tecnológico, de la combinación social del proceso de producción, del volumen y la eficiencia de los medios de producción, de las condiciones naturales, etc. Por ejemplo, la misma cantidad de trabajo se traduce, si el tiempo es propicio, en 8 fanegas de trigo y, si es desfavorable, en 4 . La misma cantidad de trabajo rinde mayor cantidad de metal en una mina rica que en otra pobre, etc. Los diamantes se dan rara vez en la superficie de la tierra, razón por la cual el extraerlos cuesta por regla general mucho tiempo de trabajo. Es así que en poco volumen ellos representan mucho trabajo. Jacob duda de que el oro haya pagado nunca todo su valor. Y esto podríamos decir, con mayor razón, de los diamantes. Según Eschwegw, en 1823, los resultados totales de la extracción de diamantes durante 80 años de trabajo en las minas de Brasil no habrían cubierto el precio del producto de año y medio en las plantaciones brasileñas de azúcar o café, a pesar de representar mucho más trabajo y, por tanto, más valor. Con minas más ricas, la misma cantidad de trabajo se materializaría en más diamantes y ello haría bajar el valor de éstos. Si se lograse convertir el carbón en diamantes con poco trabajo, su valor podría descender incluso por debajo del de los ladrillos. En general, a medida que aumenta la capacidad productiva del trabajo, disminuye la cantidad de tiempo de trabajo necesario para producir un artículo, se reduce la masa de trabajo cristalizada en él y baja, por tanto, su valor. Y a la inversa, cuando más reducida es la productividad del trabajo, más tiempo de trabajo se necesita para producir un artículo y mayor es, por tanto, el valor de éste. Por consiguiente, la magnitud del valor de una mercancía cambia en razón directa a la cantidad y en razón inversa a la productividad del trabajo que adquiere realidad en ella.

Una cosa puede ser valor de uso sin ser valor. Es lo que ocurre cuando su utilidad para el hombre no existe mediante el trabajo. Tal es el caso del aire, de la tierra virgen, de las praderas naturales, de los árboles y plantas silvestres, etc. Una cosa puede ser útil y producto del trabajo humano sin ser por ello mercancía. Quien satisface su propia necesidad con su producto crea valor de uso, pero no mercancía. Para producir mercancía, no basta con que produzca valor de uso: tiene que producirlo para otro, tiene que producir valor de uso social. [Y no sólo para otros, pura y simplemente. El campesino feudal producía el trigo del censo para el señor feudal y el trigo del diezmo para el cura. Pero ni uno ni otro eran mercancía por el simple hecho de haber sido producidos para otro. Para que el producto se vuelva mercancía, es necesario que sea transferido al otro, para quien sirve de valor de uso, por medio del intercambio]. ${ }^{11 a}$ Finalmente, ninguna cosa puede ser valor sin ser objeto de uso. Si es inútil, lo será también el trabajo contenido en él; no contará como trabajo ni creará, por tanto, ningún valor.

\section{DOBLE CARÁCTER DEL TRABAJO MATERIALIZADO EN LAS MERCANCÍAS}

Originalmente, la mercancía se nos presentó como una dualidad, valor de uso y valor de cambio. Después se descubrió que, también el trabajo cuando se halla expresado en el valor deja de poseer las mismas características que le corresponden como creador de valores de uso. He sido yo el primero en demostrar críticamente esta naturaleza dual del trabajo contenido en la mercancía. ${ }^{12} \mathrm{Y}$ como este punto es el eje entorno al cual gira la comprensión de la economía política, trataré aquí de esclarecerlo con mayor cuidado. 
Tomemos dos mercancías, por ejemplo una chaqueta y diez varas de lienzo. Supongamos que la primera tiene el doble de valor que la segunda, es decir, que si 10 varas de lienzo son $=\mathrm{v}$, la chaqueta $=2 \mathrm{v}$.

La chaqueta es un valor de uso que satisface una necesidad especial. Para producirla se requiere un determinado tipo de actividad productiva. Y ésta se determina según su fin, su modo de operar, su objeto, sus medios y su resultado. Al trabajo cuya utilidad se materializa así en el valor de uso de su producto, o en el hecho de que su producto es un valor de uso, lo llamamos concisamente trabajo útil. Desde éste punto de vista, el trabajo es siempre considerado en referencia a la utilidad de su efecto [Nutzeffekt].

Así como la chaqueta y el lienzo son valores de uso cualitativamente distintos, así también son cualitativamente distintos los trabajos mediante los cuales ellos existen: el trabajo del sastre y el del tejedor. Si aquellos dos objetos no fuesen cualitativamente distintos y, por tanto, productos de trabajo útiles cualitativamente diferente, no podrían enfrentarse el uno al otro como mercancías. Una chaqueta no se cambia por otra chaqueta, un valor de uso no se cambia por otro igual.

En la totalidad de los distintos tipos de valores de uso o cuerpos de las mercancías se materializa una totalidad de trabajos útiles igualmente múltiples y distintos en cuanto a su género, familia, especie, subespecie y variedad: una división social del trabajo. Esta es condición de existencia de la producción de mercancías, aunque la producción de mercancías no sea, a la inversa, condición de existencia de la división social del trabajo. En la comunidad de la antigua India encontramos una división social del trabajo sin que por ello los productos se conviertan allí en mercancías. $\mathrm{O}$, para poner un ejemplo más cercano a nosotros, en toda fábrica vemos que el trabajo se halla sistemáticamente dividido, pero esta división no se debe al hecho de que los obreros intercambien entre sí sus productos individuales. Solamente los productos de trabajos privados autosuficientes e independientes unos de otros se enfrentan entre sí como mercancías.

Hemos visto, pues, que en el valor de uso de toda mercancía se encuentra una determinada actividad productiva dirigida a un fin, un trabajo útil. Los valores de uso no pueden enfrentarse como mercancías si no encierran trabajos útiles cualitativamente distintos. En una sociedad cuyos productos adoptan en general la forma de mercancías, es decir, en una sociedad de productores de mercancías, esta diferencia cualitativa entre los trabajos útiles, ejercidos aquí como trabajos privados por productores independientes los unos de los otros, se desarrolla hasta formar un sistema de muchas ramificaciones, hasta una división social del trabajo.

A la chaqueta le tiene sin cuidado quien se la ponga, si el sastre o su cliente. En ambos casos actúa como valor de uso. Y tampoco cambia la relación entre la chaqueta y el trabajo que la produce por el solo hecho de que la sastrería se convierte en un oficio aparte, en un miembro autónomo de la división social del trabajo. Allí donde es acuciante la necesidad de vestido, los hombres llevaron miles de años cortando prendas antes de que algunos de ellos se volvieran sastres. Pero la existencia de la chaqueta, del lienzo, de todo elemento de la riqueza material no suministrado por la naturaleza, se debió siempre a una actividad productiva destinada a un fin específico, que asimila materias especiales de la naturaleza a necesidades humanas especiales. Así, como creador de valores de uso, como trabajo útil, el trabajo constituye una 
condición de existencia del hombre que es independiente de todas las formas de sociedad, una necesidad natural eterna que hace posible el cambio de materias entre el hombre y la naturaleza, y por tanto la vida humana.

Los valores de uso, chaqueta, lienzo, etc., en una palabra, los cuerpos de las mercancías son combinaciones de dos elementos, la materia natural y el trabajo. Si descontamos la suma total de los diversos trabajos útiles contenidos en la chaqueta, el lienzo, etc., quedará siempre un substrato material, que está allí por naturaleza, sin la intervención del hombre. En su producción, éste sólo puede obrar como obra la naturaleza misma, es decir, haciendo cambiar de forma la materia. ${ }^{13}$ Más aún. En esta labor de conformación cuenta constantemente con el apoyo de las fuerzas naturales. El trabajo no es, por tanto, la única fuente de los valores de uso producidos por él, de la riqueza material. Como dice William Petty, el trabajo es su padre y la tierra su madre.

Pasemos ahora de la mercancía como objeto de uso al valor de las mercancías.

Según el supuesto de que partimos, la chaqueta vale el doble que el lienzo. Pero esto no es más que una diferencia cuantitativa, que no nos interesa todavía. Sólo tengamos en cuenta que si el valor de una chaqueta es el doble que el de 10 varas de lienzo, 20 varas de lienzo tienen la misma magnitud de valor que una chaqueta. En cuanto valores, chaqueta y lienzo son objetos de sustancia igual, expresiones objetivas de un trabajo de la misma naturaleza. El trabajo del sastre y el del tejedor son, sin embargo, trabajos cualitativamente distintos. No obstante, hay épocas sociales [Gesellschaftszustände] en las que el mismo hombre ejecuta alternativamente el trabajo de sastre y el del tejedor, en las que estos dos tipos distintos de trabajo son, por lo tanto, solamente modalidades de trabajo del mismo individuo y aún no han adquirido el carácter de funciones fijas y específicas de diferentes individuos, tal como entre nosotros la chaqueta que hoy corta el sastre y los pantalones que corta mañana, solo presuponen distintas variantes del trabajo individual. Por otra parte, basta la simple vista para convencernos de que, en nuestra sociedad capitalista, una porción determinada del trabajo humano se encauza alternativamente en forma de trabajo de sastrería o en forma de trabajo textil, con arreglo a la tendencia variable de la demanda de trabajo. Estos cambios de forma del trabajo pueden encontrar obstáculos, pero son inevitables. Si prescindimos del carácter determinado de la actividad productiva, y por tanto, del carácter útil del trabajo, vemos que este es siempre un gasto de fuerza de trabajo humano. El trabajo del sastre y el del tejedor, aunque actividades productivas cualitativamente distintas una y otra son ambos gasto productivo de cerebro, músculos, nervios, manos, etc. humanos, y en este sentido son ambos trabajo humano. ${ }^{14}$ Se trata simplemente de dos formas diferentes de gastar la fuerza humana de trabajo. Cierto que ésta necesita hallarse ya más o menos desarrollada para poder gastarse en tal o cual forma. Pero el valor de la mercancía representa pura y simplemente trabajo humano, gasto de trabajo humano en general. Ahora bien, lo que sucede en la sociedad civil con el hombre, que en sí mismo tiene un ínfimo papel mientras es grande el que desempeña un general o un banquero, le ocurre aquí al trabajo humano. Trabajo humano es aquí el gasto de la fuerza de trabajo simple que posee por término medio todo hombre común y corriente en su organismo físico, sin necesidad de un desarrollo especial. Aunque el trabajo simple medio varíe de carácter según los diferentes países y épocas de la civilización, en cada sociedad existe como algo dado el trabajo complejo 
solo rige como trabajo simple potenciado o, por mejor decir, multiplicado, de manera que una cantidad menor de trabajo complejo equivale a otra mayor de trabajo simple. ${ }^{15} \mathrm{Y}$ la experiencia muestra que esta reducción de un trabajo a otro se efectúa constantemente. Una mercancía puede ser el producto del trabajo más complicado del mundo, pero su valor la equipara al producto del trabajo simple, razón por la cual ella misma representa solamente una determinada cantidad de trabajo simple. Las diferentes proporciones en que diferentes clases de trabajo se reducen al trabajo simple como a su unidad de medida se establecen mediante un proceso social que se efectúa a espaldas de los productores, y ello hace que éstos las tengan por obra de la tradición. Para simplificar, consideremos en lo sucesivo todo tipo de fuerza de trabajo directamente como fuerza de trabajo simple, evitándonos así sólo el esfuerzo de tener que reducirlo a ella.

Así, pues, lo mismo que en los valores chaqueta y lienzo se hace abstracción de la diferencia entre sus valores de uso en los trabajos materializados en estos valores se hace caso omiso de la diferencia que media entre sus formas útiles respectivas, entre el trabajo del sastre y el del tejedor. Así como los valores de uso chaqueta y lienzo son combinaciones de dos actividades productivas de determinadas finalidades con los dos materiales, paño e hilaza, y los valores chaqueta y lienzo, en cambio, simples plasmaciones de trabajo indistinto, así también los trabajos contenidos en estos valores no tienen vigencia por su comportamiento productivo hacia el paño o la hilaza, sino solamente como gastos de fuerza de trabajo humana. Los trabajos del sastre y del tejedor son elementos que concurren a la creación de los valores de uso chaqueta y lienzo precisamente por sus diferentes cualidades; en cambio, sustancia del valor chaqueta y del valor lienzo en tanto que se hace abstracción de sus cualidades específicas, y que ambos poseen una cualidad igual, la cualidad de trabajo humano.

Pero la chaqueta y el lienzo no son solamente valores en general, sino que son valores de una determinada magnitud; según el supuesto del que partimos, la chaqueta vale el doble que 10 varas de lienzo. ¿Y de dónde proviene esta diferencia entre sus magnitudes de valor? Sencillamente de que el lienzo sólo contiene la mitad de trabajo que la chaqueta, lo que quiere decir que para producir ésta la fuerza de trabajo debe ser gastada durante el doble del tiempo necesario para producir aquél.

Así pues, si con respecto al valor de uso el trabajo contenido en la mercancía interesa sólo cuantitativamente, en lo tocante a la magnitud del valor interesa sólo cuantitativamente, una vez que se encuentra reducido ya a trabajo humano despojado de toda otra cualidad. En el primer caso se trata del qué y del cómo del trabajo, en el segundo de su cuánto, de su duración en el tiempo. Y cómo la magnitud del valor de una mercancía sólo representa la cantidad de trabajo contenida en ella, distintas mercancías, establecidas en cierta proporción, son siempre necesariamente valores iguales.

$\mathrm{Si}$, por ejemplo, la productividad de todos los trabajos útiles necesarios para la producción de una chaqueta permanece inalterable, la magnitud del valor de la suma de todas las chaquetas aumentará al aumentar su cantidad. Si 1 chaqueta representa x jornadas de trabajo, 2 chaquetas representarán $2 \mathrm{x}$ jornadas de trabajo etc. Pero supongamos que el trabajo necesario para producir una chaqueta aumenta al doble a o se reduce a la mitad. En el primer caso, una chaqueta valdrá ahora tanto como antes dos y, en el segundo, dos chaquetas pasarán a tener el valor 
que antes tenía una sola, a pesar de que ambos casos la chaqueta seguirá prestando los mismos servicios que antes y de que el trabajo útil contenido en esta prenda no habrá mejorado ni empeorado de calidad. Lo que ha cambiado es la cantidad de trabajo gastado en su producción.

Una cantidad mayor de valor de uso constituye de por sí mayor riqueza material, dos chaquetas más que una. Con dos chaquetas pueden vestirse dos hombres, con una solamente uno, etc. Sin embargo, al aumento del volumen de la riqueza material puede corresponder un descenso simultáneo de su magnitud de valor. Este movimiento contradictorio brota del carácter dual del trabajo. Naturalmente, la productividad es siempre productividad de un trabajo útil, concreto, y solo determina en realidad, el grado de rendimiento que tiene una actividad encaminada a un fin productivo en un lapso de un tiempo dado. Por tanto, el trabajo útil será una fuente más copiosa o más escasa de productos en relación directa con el aumento o la disminución de su productividad. En cambio, las variaciones de la productividad, de por sí no afectan para nada, al trabajo materializado en el valor. Como la productividad pertenece a la forma útil concreta del trabajo, es natural que, en cuanto se hace abstracción de ésta, la productividad deja de afectar al trabajo. Por consiguiente, el mismo trabajo arrojará en el mismo lapso de tiempo la misma magnitud de valor, por mucho que cambie su productividad. Pero suministrará en el mismo lapso de tiempo diferente cantidad de valor de uso, mayor si la productividad aumenta, y menos si disminuye. El mismo cambio operado en la capacidad productiva que aumenta la fecundidad del trabajo y, por tanto, el volumen de los valores de uso suministrados por él, disminuirá la magnitud de valor de este volumen total incrementado si reduce la suma del tiempo de trabajo necesario para su producción. E igualmente a la inversa.

De una parte, todo trabajo es gasto de fuerza de trabajo humano en sentido fisiológico; con esta cualidad de trabajo humano igual o trabajo humano abstracto, crea el valor de las mercancías. De otra parte y al mismo tiempo, todo trabajo es gasto de fuerza de trabajo humano bajo una forma específica encaminada a un fin; con esta cualidad, de trabajo útil concreto, produce valores de uso. ${ }^{16}$

\section{LA FORMA DEL VALOR O EL VALOR DE CAMBIO}

Las mercancías vienen al mundo en forma de valores de uso o de cuerpos de las mercancías, como el hierro, el lienzo, trigo, etc. Es ésta su forma natural original. Pero sólo son mercancías gracias a que son algo doble: objetos de uso y, al mismo tiempo, portadoras de valor. Por tanto, sólo aparecen o se presentan como mercancías, sólo poseen la forma de mercancías cuando poseen esa doble forma: una forma natural y una forma valor.

La objetividad de valor de las mercancías se distingue de Wittib Hurtig en que no se sabe dónde encontrarla. Exactamente al contrario de lo que ocurre con la objetividad tosca y tangible del cuerpo de las mercancías, en su objetividad de valor no entra ni un sólo átomo de materia natural. Por muchas vueltas que le demos a una mercancía, como objeto de valor será siempre intangible. Pero recordemos que las mercancías sólo poseen una objetividad de valor en cuanto son critalizaciones de la misma unidad social que es el trabajo humano, y que su objetitividad de valor, por tanto, es algo puramente social; así es de suyo comprensible que tal objetividad sólo puede manifestarse en la relación social de una mercancía con otra. En efecto, 
nuestro punto de partida fue el valor de cambio o relación proporcional de intercambio entre las mercancías; escondido en él, llegamos a descubrir el valor de las mercancías. Debemos ahora retornar a esa forma de manifestación del valor.

Todo el mundo sabe, aunque no sepa otra cosa, que las mercancías poseen en común una forma de ser valores, que contrasta muy llamativamente con las abigarradas formas naturales de sus valores de uso: la forma de dinero. Sin embargo, de lo que se trata aquí es de realizar algo que la economía burguesa ni siquiera ha intentado, a saber: comprobar la génesis de esta formadinero, es decir, seguir el desarrollo de la expresión del valor, contenida en la relación proporcional de valor entre las mercancías, desde su figura más simple y menos evidente hasta la fascinante forma en dinero. Al realizar esto, desaparece al mismo tiempo el enigma del dinero.

La relación de valor más simple es, evidentemente, la proporción de valor entre una mercancía y otra mercancía singular distinta de ella, cualquiera que esta sea. La relación proporcional de valor entre dos mercancías suministra, por tanto, la expresión más simple del valor de una mercancía.

\section{A) LA FORMA SIMPLE SINGULAR O FORTUITA DEL VALOR}

$\mathrm{x}$ mercancía $\mathrm{A}=\mathrm{y}$ mercancía $\mathrm{B}$, o x mercancía $\mathrm{A}$ vale y mercancía. ( 20 varas de lienzo $=1$ chaqueta, 020 varas de valen 1 chaqueta).

1. LOS DOS POLOS DE LA EXPRESIÓN DEL VALOR. FORMA VALOR RELATIVA Y FORMA EQUIVALENCIAL

El secreto de toda forma del valor se encierra en esta forma simple de valor. Es en su análisis, por tanto, donde reside la verdadera dificultad

Aquí, dos mercancías distintas, А у в, en nuestro ejemplo lienzo y chaqueta, desempeñan evidentemente dos papeles distintos. El lienzo expresa su valor en la chaqueta, la chaqueta sirve como material de esta expresión de valor. La primera mercancía desempeña un papel activo, la segunda un papel pasivo. El valor de la primera mercancía se representa como valor relativo, es decir, esta mercancía se halla en forma valor relativa. La segunda mercancía funciona como equivalente o se encuentra en forma equivalencial.

Forma valor relativa y forma equivalencial constituyen una unidad, son dos momentos inseparables que se copertenecen entre sí, que se condicionan mutuamente, pero son al mismo tiempo extremos que se excluyen o contraponen recíprocamente, es decir, polos de la misma expresión del valor; estos dos papeles se reparten siempre entre las dos distintas mercancías relacionadas entre sí por una expresión de valor. No podemos, por ejemplo, expresar el valor del lienzo en lienzo. 20 varas de lienzo $=20$ varas de lienzo no es una expresión de valor. Esta ecuación dice más bien lo contrario: que 20 varas de lienzo son simplemente 20 varas de lienzo, una determinada cantidad del objeto de uso lienzo. Por tanto, el valor del lienzo sólo puede expresarse en términos relativos, es decir, en otra mercancía. La forma valor relativa en el lienzo presupone, por consiguiente, que otra mercancía cualquiera adopta frente a ella la forma equivalencial. Además, esta otra mercancía que figura como equivalente no puede encontrarse al 
mismo tiempo en la forma valor relativa. No es ella la que expresa su valor. Se limita a suministrar el material para la expresión del valor de otra mercancía.

Es cierto que la expresión: 20 varas de lienzo = 1 chaqueta o 20 varas de lienzo valen una chaqueta implica también la relación inversa: 1 chaqueta $=20$ varas de lienzo o una chaqueta vale 20 varas de lienzo. Pero, para expresar en sentido relativo el valor de la chaqueta, tengo que invertir la ecuación y, al hacerlo, el que se convierte en equivalente es el lienzo en vez de la chaqueta. La misma mercancía no puede, pues, aparecer simultáneamente en ambas formas en una misma expresión de valor. Estas dos formas se excluyen la una a la otra como dos polos.

El que una mercancía adopte la forma valor relativa o la forma contrapuesta de equivalente depende exclusivamente de la posición que ocupe en cada caso en la expresión del valor, es decir, de que sea la mercancía cuyo valor se expresa o aquélla en que un valor es expresado.

\section{LA FORMA VALOR RELATIVA}

\section{a) CONTENIDO DE LA FORMA VALOR RELATIVA}

Para descubrir cómo la expresión simple de valor de una mercancía se halla contenida en la relación de valor entre dos mercancías, hay que empezar por considerar esta relación con independencia total de su aspecto cuantitativo. En la mayoría de los casos se procede precisamente al revés y sólo se ve en la relación de valor la proporción en que resultan igualables entre sí determinadas cantidades de dos clases de mercancías.

Se pasa por alto que las magnitudes de cosas diferentes sólo se vuelven comparables cuantitativamente después de su reducción a la misma unidad. Sólo en cuanto expresiones de la misma unidad son magnitudes del mismo orden y, por tanto, conmensurables. ${ }^{17}$

Ya sean 20 varas de lienzo $=1$ chaqueta $\mathrm{o}=20 \mathrm{o}=\mathrm{x}$ chaquetas, es decir, ya valga una determinada cantidad de lienzo muchas o pocas chaquetas, cada una de estas proporciones implica siempre que el lienzo y las chaquetas, en cuanto magnitudes de valor, son expresiones de la misma unidad, objetos de la misma naturaleza. Lienzo = chaqueta: este es el fundamento de la ecuación.

Pero las dos mercancías igualadas cualitativamente no desempeñan el mismo papel. Lo que se expresa es sólo el valor del lienzo. Y ¿cómo? Mediante su referencia a la chaqueta como su «equivalente» o como algo por lo que él mismo es «intercambiable». En esta relación, la chaqueta rige como forma de existencia del valor, como objeto-valor, pues solamente en cuanto tal es ella lo mismo que el lienzo. Y, de otra parte, el propio ser valor del lienzo se revela o recibe una expresión autónoma, ya que solamente en cuanto valor es el referible a la chaqueta como algo de igual valor o intercambiable por él. Así, por ejemplo, el ácido butírico es un cuerpo distinto del formiato de propilo. Uno y otro, sin embargo, están formados por las mismas sustancias químicas, carbono (C), hidrógeno $(\mathrm{H})$ y oxígeno (o), y además en la misma combinación cuantitativa, a saber $\mathrm{C} 4 \mathrm{H} 8 \mathrm{O} 2$. Ahora bien, dentro de una relación en la que equiparásemos el formiato de propilo al ácido butírico, lo que haríamos sería: en primer lugar, considerar al formiato de propilo simplemente como forma de existencia de $\mathrm{C} 4 \mathrm{H} 8 \mathrm{O} 2 \mathrm{y}$, en segundo lugar, decir que también el ácido butírico está formado por $\mathrm{C} 4 \mathrm{H} 8 \mathrm{O} 2$. Por lo tanto, mediante la equiparación del formiato de propilo al ácido butírico, la sustancia química del segundo estaría expresada a diferencia de su forma corpórea. 
Si decimos que, en cuanto valores, las mercancías no son más que plasmaciones de trabajo humano, nuestro análisis reduce las mercancías a la abstracción valor, pero no les da una forma valor distinta de sus formas naturales. No sucede así en la relación de valor de una mercancía con otra. Aquí, su carácter de valor se destaca mediante su propia referencia a la otra mercancía.

Cuando, por ejemplo, equiparamos la chaqueta como objeto-valor al lienzo, equiparamos el trabajo contenido en aquella al trabajo contenido en éste. Ahora bien, el trabajo del sastre que hace la chaqueta es un trabajo concreto, distinto del trabajo del tejedor que hace el lienzo. Pero, al equiparar el trabajo del sastre al trabajo del tejedor, reducimos de hecho el trabajo del primero a lo que hay de realmente igual en ambos trabajos, a su carácter común de trabajo humano. Mediante este rodeo, decimos que tampoco el trabajo del tejedor, en cuanto tejer valor, posee ninguna característica que lo diferencie del trabajo del sastre, decimos que él también es trabajo humano abstracto. Sólo la expresión de equivalencia entre mercancías de distinta clase pone de manifiesto el carácter específico del trabajo creador de valor, al reducir realmente los diferentes trabajos contenidos en las diferentes mercancías a lo que tienen de común, a trabajo humano en general. ${ }^{17 a}$

No basta, sin embargo, con expresar el carácter específico del trabajo en que consiste el valor del lienzo. La fuerza de trabajo humana en estado fluido, o trabajo humano, crea valor, pero no es valor. Se convierte en valor cuando se halla en estado de condensación, en forma objetivada. Para expresar el valor del lienzo como plasmación de trabajo humano, es necesario expresarlo como una «objetividad» materialmente distinta del propio lienzo y al mismo tiempo común a él y a otra mercancía. El problema está ya resuelto.

En la relación de valor del lienzo, la chaqueta rige como algo cualitativamente igual a él, como un objeto de la misma naturaleza, porque es un valor. Rige aquí, por tanto, como una cosa en que se manifiesta el valor o que en su forma natural tangible representa valor. Cierto que la chaqueta, el cuerpo de la mercancía chaqueta, es un simple valor de uso. Una chaqueta no expresa valor, como lo expresa el primer trozo de lienzo con que nos encontremos. Lo cual sólo demuestra que, dentro de la relación de valor con el lienzo, la chaqueta significa más que fuera de ella, a la manera como ciertos hombres embutidos en una chaqueta galoneada significan más que cuando no la visten.

En la producción de la chaqueta se ha gastado realmente fuerza de trabajo humana, bajo la forma del trabajo del sastre. Se ha acumulado en ella, por tanto, trabajo humano. Vista por este lado, la chaqueta es "portadora de valor» aunque no deje trasparentar esta cualidad suya por más raída que se encuentra. Y en la relación de valor del lienzo sólo rige en este aspecto, es decir, en cuanto valor que ha adquirido cuerpo o en cuanto cuerpo de valor. Aunque haya estado abotonada, el lienzo ha descubierto en ella la bella alma del valor emparentada con la suya. Pero la chaqueta no puede representar valor ante el lienzo sin que al mismo tiempo, el valor adopte para el lienzo la forma de una chaqueta. Del mismo modo que el individuo A no puede comportarse ante el individuo в como ante un monarca sin que para A la majestad adopte al mismo tiempo la figura corpórea de в у se identifique, por tanto, con los rasgos del rostro, el pelo y otras cosas propias del rey de que se trate.

En la relación de valor en que la chaqueta constituye el equivalente del lienzo, la forma de chaqueta rige, pues, en tanto que forma valor. Por consiguiente el valor de la mercancía lienzo 
se expresa en el cuerpo de la mercancía chaqueta; el valor de una mercancía en el valor de uso de la otra. En tanto que el valor de uso, el lienzo es una cosa materialmente distinta de la chaqueta; en tanto que el valor es «tal como la chaqueta» y adquiere, por tanto, el aspecto de una chaqueta. Asume así una forma valor distinta de su forma natural. Su ser valor se manifiesta en su igualdad con la chaqueta como la naturaleza ovina del cristiano se revela en su igualdad con el Cordero de Dios.

Como vemos, todo lo que de antemano nos había dicho el análisis del valor de la mercancía nos lo dice el lienzo mismo tan pronto como entra en tratos con otra mercancía, como la chaqueta. Sólo que delata sus pensamientos en el único lenguaje que le es usual, el lenguaje de las mercancías. Para decir que lo que constituye su propio valor es el trabajo en su cualidad abstracta de trabajo humano, dice que la chaqueta, en tanto que es para él su igual, es decir, en tanto que es valor, está compuesta por el mismo trabajo que lo compone a él. Para decirnos que su sublime objetividad de valor es distinta de su almidonado cuerpo de lienzo, nos dice que el valor tiene el aspecto de una chaqueta y que, por tanto, él mismo, en cuanto objeto-valor, es igual a la chaqueta como un huevo a otro huevo. Dicho sea de pasada, el lenguaje de las mercancías tiene muchos dialectos, más o menos correctos, además del hebreo. El término alemán Wertsein [ser valor], por ejemplo, expresa menos tajantemente que las palabras latinas $v a-$ lere, valer, valoir el hecho de que la equiparación de la mercancía в a la mercancía A es la propia expresión de valor de ésta última. París vaut bien une messe! [¡París bien vale una misa!].

En virtud de la relación de valor, la forma natural de la mercancía в se convierte en la forma valor de mercancía A o el cuerpo de aquella en espejo del valor de ésta. ${ }^{18} \mathrm{Al}$ referirse a la mercancía в como cuerpo-valor, como materialización de trabajo humano, la mercancía A se hace del valor de uso в el material de su propia expresión de valor. El valor de la mercancía A, expresado así en el valor de uso de la mercancía B, posee la forma de valor relativo.

\section{b) DETERMINACIÓN CUANTITATIVA DE LA FORMA VALOR RELATIVA}

Toda la mercancía cuyo valor se trata de expresar es un objeto de uso de cantidad determinada, 15 fanegas de trigo, 100 libras de café, etc. Esta cantidad dada de mercancías contiene una determinada cantidad de trabajo humano. Por tanto, la forma de valor no expresa solamente valor en general, sino un valor cuantitativamente determinado o una magnitud de valor. Así, pues, en la relación de valor de la mercancía A con la mercancía B, del lienzo con la chaqueta, no sólo se equipara cualitativamente el tipo de mercancía chaqueta, como cuerpovalor en general, al lienzo, sino que a una determinada cantidad de lienzo, por ejemplo a 20 varas de lienzo, se le equipara una determinada cantidad del cuerpo-valor o equivalente, por ejemplo, una chaqueta.

La ecuación « 20 varas de lienzo = 1 chaqueta o 20 varas de lienzo valen una chaqueta» presuponen que una chaqueta se contienen exactamente la misma cantidad de sustancia de valor que en 20 varas de lienzo, es decir, que ambas cantidades de mercancías han costado igual cantidad de trabajo o tiempo de trabajo igual. Pero el tiempo de trabajo necesario para producir 20 varas de lienzo o una chaqueta cambia al cambiar la capacidad productiva del trabajo del tejedor o del trabajador del sastre. Veamos más de cerca cómo influyen estos cambios en la expresión relativa de la magnitud del valor. 
I. El valor del lienzo cambia, ${ }^{19}$ mientras que el valor de la chaqueta se mantiene constante. Si el tiempo de trabajo necesario para producir el lienzo se duplica, a consecuencia por ejemplo del menor rendimiento de la cosecha de lino, se duplicará también su valor. En vez de 20 varas de lienzo igual a una chaqueta, tendremos que 20 varas de lienzo $=2$ chaquetas, ya que 1 chaqueta sólo contiene ahora la mitad del tiempo de trabajo que 20 varas de lienzo. En cambio, si el tiempo de trabajo necesario para producir el lienzo desciende a la mitad, al perfeccionarse los telares, por ejemplo, descenderá también a la mitad el valor del lienzo. Por tanto, ahora, 20 varas de lienzo $=1 / 2$ chaqueta. El valor relativo de la mercancía $\mathrm{A}$, o sea su valor expresado en la mercancía в aumenta o disminuye, por tanto, en razón directa al aumento o disminución del valor de la mercancía A, siempre y cuando que el valor de la mercancía B permanezca inalterado.

II. El valor del lienzo permanece constante, mientras que el valor de la chaqueta cambia. $\mathrm{Si}$, en estas circunstancias, se duplica el tiempo de trabajo necesario para la producción de la chaqueta, a consecuencia, supongamos, de que al esquilar las ovejas se obtenga un rendimiento menor, tendremos, en vez de 20 varas de lienzo $=1$ chaqueta: 20 varas de lienzo $=1 / 2$ chaqueta. En cambio, si el valor de la chaqueta baja a la mitad, la formula se invertirá: 20 varas de lienzo $=2$ chaquetas. Es decir que, manteniéndose inalterable el valor de la mercancía $\mathrm{A}$, su valor relativo, o expresado en la mercancía $\mathrm{B}$, aumentará o disminuirá en razón inversa al cambio de valor de $\mathbf{B}$.

Comparando los distintos casos considerados en I y II, tendremos que el mismo cambio de magnitud del valor relativo puede ser el resultado de causas completamente opuestas. Así, la fórmula 20 varas de lienzo $=1$ chaqueta se convierte: 1 ) en la ecuación 20 varas de lienzo $=2$ chaquetas, bien porque el valor del lienzo se duplique o bien porque el valor de las chaquetas descienda a la mitad, y 2) en la ecuación 20 varas de lienzo $=1 / 2$ chaqueta, sea porque el valor del lienzo baje a la mitad o porque el valor de la chaqueta aumente al doble.

III. Las cantidades de trabajo necesarias para la producción del lienzo y la chaqueta pueden cambiar simultáneamente en el mismo sentido y en idéntica proporción. En este caso, 20 varas de lienzo seguirán siendo, al igual que antes, = 1 chaqueta, cualquiera que sea el cambio experimentado en sus valores. Su variación de valor se descubre al comparar estas dos mercancías con una tercera cuyo valor permanezca constante. Si los valores de todas las mercancías aumentaran o disminuyeran simultáneamente y en la misma proporción, sus valores relativos permanecerían invariables. Sus variaciones de valor reales se translucirían en el hecho de que el mismo tiempo de trabajo suministraría ahora, en general, una cantidad de mercancías mayor o menor que antes.

IV. Los tiempos de trabajo necesarios respectivamente para la producción de lienzo y chaquetas y, por tanto, los valores de éstos pueden variar simultáneamente en el mismo sentido, pero en distinto grado; pueden variar en sentido opuesto, etc. para averiguar la influencia que todas estas posibles combinaciones ejercen sobre el valor relativo de una mercancía no hay más que aplicar los casos I, II y III.

Por lo tanto, los cambios reales de la magnitud de valor no se reflejan de un modo inequívoco ni exhaustivo en su expresión relativa o en la magnitud del valor relativo. El valor relativo de una mercancía puede variar aunque su valor permanezca constante. Su valor relativo 
puede permanecer constante aunque varíe su valor. Y, por último, las variaciones simultáneas de su magnitud de valor y de la expresión relativa de esta, no tiene por qué coincidir entre si necesariamente, ni mucho menos. ${ }^{20}$

\section{LA FORMA EQUIVALENCIAL}

Hemos visto que en cuanto la mercancía A (el lienzo) expresa su valor en el valor de uso de una mercancía distinta в (la chaqueta), imprime a ésta una forma valor peculiar, la forma equivalencial. El lienzo en tanto que mercancía manifiesta su propio ser valor en el hecho de que la chaqueta rige para él como su igual, sin que para esto ella necesite revestir una forma valor distinta de su forma corpórea. Así, el lienzo expresa efectivamente su propio ser valor gracias al hecho de que la chaqueta es directamente intercambiable por él. ${ }^{* *}$ La forma equivalencial de una mercancía es, por consiguiente, la forma de su intercambiabilidad inmediata por otra.

Pero el que una clase de mercancías, la chaqueta, sirva de equivalente a otra clase de mercancías, el lienzo; el que, por tanto, las chaquetas reciban la propiedad característica de encontrarse en la forma de la intercambiabilidad directa por lienzo, no indica en modo alguno la proporción en que uno y otras son cambiables entre sí. Esta proporción dependerá, puesto que la magnitud de valor del lienzo está dada, de la magnitud de valor de las chaquetas. Sea que, en la expresión de valor, la chaqueta se encuentre como equivalente y el lienzo como valor relativo o, por el contrario, el lienzo como equivalente y la chaqueta como valor relativo, la magnitud de valor de la chaqueta dependerá siempre del tiempo de trabajo necesario para su producción y se determinará, por tanto, independientemente de la forma valor que ella adopte. Pero, tan pronto como la clase de mercancías chaqueta pasa a ocupar en la expresión de valor el lugar del equivalente, su magnitud de valor carece de expresión en tanto que magnitud de valor. La mercancía chaqueta figura en la ecuación de valor simplemente como una determinada cantidad de una cosa.

Por ejemplo, 40 varas de lienzo «valen»... ¿qué?: 2 chaquetas. Puesto que la clase de mercancías chaqueta desempeña aquí la función de equivalente, y que por tanto el valor de uso chaqueta actúa con respecto al lienzo como cuerpo-valor, basta con una determinada cantidad de chaquetas para expresar una determinada cantidad del valor lienzo. Por tanto, 2 chaquetas pueden expresar la magnitud de valor de 40 varas de lienzo, pero no pueden expresar jamás su propia magnitud de valor, la magnitud de valor de las chaquetas. La visión superficial de este hecho, del que el equivalente, en la ecuación de valor, no posee nunca más que la forma de una simple cantidad de una cosa, de un valor de uso, indujo a Bailey y a muchos autores que le anteceden y le siguen a ver falsamente en la expresión de valor una relación puramente cuantitativa. ${ }^{* * *}$ Por el contrario, la forma equivalencial de una mercancía no encierra una determinación cuantitativa de su valor.

La primera peculiaridad que salta a la vista cuando se considera la forma equivalencial es ésta: el valor de uso se convierte en la forma de manifestación de su contrario, el valor.

La forma natural de la mercancía se torna forma valor. Pero, nótese bien, este quid pro quo [sustitución] se da para una mercancía в (chaqueta, trigo, hierro, etc.) sólo dentro de la relación de valor que se establece con ella otra mercancía A cualquiera (lienzo, etc.), y solamente dentro de esta conexión. Puesto que ninguna mercancía puede referirse a sí misma como equivalente 
ni, por tanto, hacer de su propia piel natural la expresión de su propio valor, tiene necesariamente que referirse a otra mercancía en tanto que equivalente, es decir, tiene que hacer de la piel natural de otra mercancía su propia forma valor.

Para ilustrar esto que decimos, podemos tomar el ejemplo de una medida que pertenece a los cuerpos de las mercancías en cuanto tales, es decir, en cuanto valores de uso. Un pilón de azúcar, por ser un cuerpo, es pesado [schwere] y, por tanto, tiene un peso [Gewicht]; pero este peso no es algo que sea visible o palpable en un pilón de azúcar. Tomemos ahora diferentes piezas de hierro, cuyo peso se ha establecido de antemano. La forma corpórea del hierro, de por sí, no es forma de manifestación de la pesantez [Shwerwe], como tampoco lo es la forma corpórea del pilón de azúcar. Sin embargo, para expresar el pilón de azúcar en cuanto pesantez [Shwerwe], establecemos una relación de peso [Gewicht] entre él y el hierro. Dentro de esta relación, consideramos al hierro como un cuerpo que no presenta otra cosa que pesantez. De este modo, ciertas cantidades de hierro sirven de medida de peso del azúcar y representan, frente al cuerpo del azúcar, la figura pura y simple de la pesantez, la forma en que ésta se manifiesta. El hierro desempeña este papel sólo dentro de la relación que entabla con él, el azúcar o cualquier otro cuerpo cuyo pese se trata de determinar. Si ambos objetos no fuesen pesados [Shwerwe], no podrían entrar en esta relación ni servir el uno de expresión del peso [Shwerwe] del otro. Si los ponemos a los dos en la balanza, vemos en efecto que, en tanto que pesantez, ambos son lo mismo y que, por tanto, en determinada proporción, son también del mismo peso [Gewicht]. Pues bien, así como el cuerpo del hierro en cuanto medida de peso sólo es para el pilón de azúcar representante de la pesantez, así en nuestra expresión de valor, el cuerpo chaqueta sólo es para el lienzo representante del valor.

Pero aquí termina la analogía. En la expresión de peso del pilón de azúcar, el hierro representa a una propiedad natural común a ambos cuerpos, que a su pesantez, mientras que en la expresión del valor del lienzo la chaqueta representa a una propiedad sobrenatural de ambas cosas: su valor, algo puramente social.

Por cuanto que la forma de valor relativa de una mercancía, por ejemplo el lienzo, expresa su ser valor como algo absolutamente distinto de su cuerpo y de sus propiedades corpóreas, por ejemplo, como algo igual a la chaqueta, esta expresión indica ya por sí misma que oculta una relación social. Con la forma equivalencial ocurre lo contrario. Esta consiste precisamente en que el cuerpo de una mercancía, la chaqueta, por ejemplo, la cosa misma, tal como es y como se la ve, expresa valor, es decir, posee, por naturaleza, forma valor. Cierto es que esto sólo tienen vigencia dentro de la relación de valor en que la mercancía lienzo se refiere a la mercancía chaqueta como equivalente. ${ }^{21}$ Pero como las propiedades de una cosa no brotan de su relación con otras, sino que simplemente se actualizan en esta relación, parece como si también la chaqueta poseyera por naturaleza su forma de equivalente, su propiedad de ser directamente intercambiable, ni más ni menos que sus propiedades de ser un cuerpo pesado o de conservar el calor. De ahí el carácter misteriosos de la forma equivalencial, que la mirada burda del economista sólo alcanza a descubrir cuando esta forma se presenta ante él, ya lista y acabada, en el dinero. Este trata entonces de escamotear con sus explicaciones [wegklären] el carácter místico del oro y la plata, remplazándolos con mercancías menos fascinantes y recitando con júbilo constantemente renovado el catálogo de toda la chusma de mercancías que en su día desempeñaron la función 
de equivalente mercantil. No sospecha siquiera que la más simple expresión del valor, tal como 20 varas de lienzo = 1 chaqueta, despliega ya ante nosotros el misterio de la forma equivalencial.

El cuerpo de la mercancía que sirve de equivalente actúa siempre como materialización del trabajo humano abstracto y es siempre producto de un determinado trabajo útil, concreto. Este trabajo concreto se convierte, por tanto, en expresión del trabajo humano abstracto. Si consideramos, por ejemplo, la chaqueta como mera realización, el trabajo del sastre que se realiza efectivamente en ella será una mera forma de realización de trabajo humano en abstracto. En la expresión de valor del lienzo, la utilidad del trabajo del sastre no consiste en hacer trajes - y por tanto, personalidades - sino en hacer un cuerpo al que se le ve que es valor, es decir, cristalización de trabajo, de un trabajo que no se distingue absolutamente en nada del que se halla objetivado en el valor del lienzo. Para poder crear semejante espejo del valor, el trabajo del sastre necesita no reflejar por su parte nada que no sea su cualidad abstracta consistente en ser pura y exclusivamente trabajo humano.

Bajo la forma del trabajo del sastre como bajo la del trabajo del tejedor, se gasta fuerza de trabajo humano. Ambas formas comparten, por tanto, la cualidad general de ser trabajo humano, razón por la cual pueden, en determinados casos, por ejemplo en la producción de valor, considerarse solamente desde este punto de vista. Todo esto no tiene nada de misterioso. Pero, en la expresión de valor de la mercancía, la cosa aparece invertida. Para expresar, por ejemplo, que el trabajo de tejer no crea el valor del lienzo en su forma concreta de trabajo textil, sino en su cualidad general de trabajo humano, se le enfrenta, en calidad de forma tangible de realización del trabajo humano en abstracto, el trabajo del sastre, el trabajo concreto que produce el equivalente del lienzo.

Por lo tanto, una segunda peculiaridad de la forma equivalencial es que en ella el trabajo concreto se convierte en la forma de manifestación de lo contrario de él, es decir, del trabajo humano en abstracto.

Pero, este trabajo concreto, el del sastre, al ser considerado como mera expresión del trabajo humano indiferenciado, posee la forma de la igualdad con otro trabajo, el trabajo encerrado en el lienzo, y es, por tanto, aunque trabajo privado al igual que todos los otros trabajos productores de mercancías, al mismo tiempo, y sin embargo de ello, trabajo en forma directamente social. Precisamente por ello, el producto en que se representa es un producto que puede intercambiarse directamente por otra mercancía. Por tanto, una tercera peculiaridad de la forma equivalencial es que en ella el trabajo privado se convierte en la forma de su propio contrario, en trabajo de forma directamente social.

Las dos últimas características de la forma equivalencial resultan todavía más claras si nos remontamos hasta el gran investigador que fue el pionero en analizar la forma del valor, así como tantas otras formas: del pensamiento, de la sociedad y de la naturaleza. Nos referimos a Aristóteles.

Aristóteles empieza expresando claramente que la forma dinero de la mercancía no es sino la figura más desarrollada de la forma simple del valor, esto es, de la expresión del valor de una mercancía en otra mercancía cualquiera, pues dice:

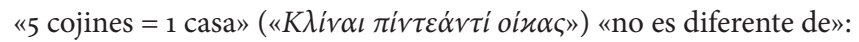

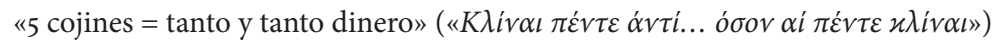


Advierte, a continuación, que la relación de valor en que esta expresión de valor se halla inserta implica, a su vez, el que la casa se equipare cualitativamente al cojín, y que estas dos cosas materialmente distintas entre sí no podrían relacionarse la una con la otra en cuanto a magnitudes conmensurables, de no mediar entre ellas esa identidad de esencia. «No puede haber intercam-

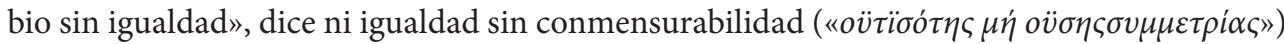
que cosas tan distintas sean conmensurables entre sí. Pero, al llegar aquí, se queda perplejo y

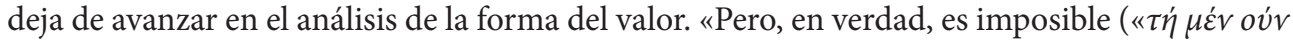

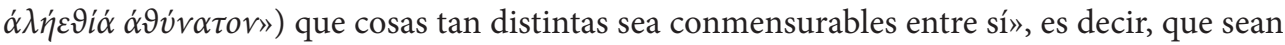
cualitativamente iguales. Esta equiparación sólo puede ser algo ajeno a la verdadera naturaleza de las cosas, es decir, sólo un «expediente para resolver una necesidad práctica».

El propio Aristóteles nos dice, por tanto, cuál es el escollo que le impide continuar su análisis: la ausencia del concepto del valor. ¿Qué es lo idéntico, es decir, la sustancia común que la casa representa para el cojín, en la expresión de valor de éste? Es «imposible en verdad» que eso pueda «existir», dice Aristóteles. ¿Por qué? La casa representa frente al cojín algo igual, en la medida en que este algo es lo que en ambos, en el cojín y en la casa, hay realmente de igual, y este algo igual es el trabajo humano.

Ahora bien, Aristóteles no podía descifrar [herauslesen] en la sola forma del valor el hecho de que, bajo la forma de valores mercantiles, todos los trabajos se encuentran expresados como trabajo humano igual, y por tanto como equivalentes, porque la sociedad griega se fundaba en el trabajo de los esclavos, la razón por la cual tenía como base natural la desigualdad entre los hombres y entre sus fuerzas de trabajo. El secreto de la expresión del valor, la igualdad y la validez igual de todos los trabajos, por ser y en la medida en que son trabajo humano en general, sólo puede llegar a descifrarse [entziffern] cuando ya el concepto de la igualdad humana ha adquirido la solidez de un prejuicio popular. Y esto sólo puede ocurrir en una sociedad en la que la forma mercancía sea la forma general del producto del trabajo y en la que, por tanto, la relación social dominante sea la relación de los hombres entre sí en cuanto propietarios de mercancías. El genio de Aristóteles brilla precisamente en el hecho de haber descubierto en la expresión del valor de las mercancías una relación de igualdad. Y fue solo el límite histórico de la sociedad en que vivía el que le impidió descubrir en qué consiste «en verdad» esta relación de igualdad.

\section{LA TOTALIDAD DE LA FORMA SIMPLE DEL VALOR}

La forma simple del valor de una mercancía se encuentra contenida en la relación proporcional de valor que ella guarde con una mercancía distinta o en su relación proporcional de intercambio con la misma. El valor de la mercancía A se expresa cualitativamente mediante la intercambiabilidad inmediata de la mercancía в por la mercancía A. Cualitativamente, se expresa mediante la intercambiabilidad de una determinada cantidad de la mercancía в por la cantidad dada de la mercancía A. En otros términos: el valor de una mercancía se halla expresado autónomamente mediante su presencia como "valor de cambio». Al comenzar este capítulo decíamos, lisa y llanamente, que la mercancía es valor de uso y valor de cambio: pero esto es, en rigor, falso. La mercancía es valor de uso u objeto de uso y «valor». Y se presenta como este algo doble que es, tan pronto como su valor posee una forma propia de manifestarse, 
distinta de su forma natural, la forma de valor de cambio; forma que no posee nunca aisladamente considerada, sino siempre solamente en su relación de valor o de intercambio con otra mercancía diferente de ella. Una vez que se sabe esto, aquella manera usual de expresarse no perturba, en nada y sirve para abreviar.

Nuestro análisis ha demostrado que la forma del valor o la expresión del valor de la mercancía brota de la naturaleza del valor mercantil, y no a la inversa, el valor y la magnitud del valor de su modo de manifestarse como valor de cambio. Esta es, sin embargo, la quimera de que se dejan llevar tanto los mercantilistas y sus modernos restauradores, tales como Ferrier, Ganilh y otros, ${ }^{22}$ como también sus antípodas, los modernos viajantes de comercio del librecambio, los Bastiat y consortes. Los mercantilistas hacen hincapié en el aspecto cualitativo de la expresión de valor y, por tanto, en la forma equivalencial de la mercancía, cuya figura acabada es el dinero; por su parte, los modernos vendedores ambulantes del libre cambio, empeñados en colocar a todo trance su mercancía, ponen el acento en el aspecto cuantitativo de la forma valor relativa. Para ellos, por consiguiente, ni el valor ni la magnitud de valor existen fuera de su expresión en la proporción de intercambio, lo que quiere decir que sólo existen en los boletines diarios de cotización de precios. El escocés Macleod, cuyo oficio consiste en vestir con el ropaje más erudito posible las confusas y rematadamente falsas ideas de Lombardstreet, constituye la síntesis por fin lograda de los supersticiosos mercantilistas y los ilustrados mercachifles librecambistas.

La consideración detenida de la expresión del valor de la mercancía A, contenida en su relación de valor con la mercancía $\mathrm{B}$, ha mostrado que en ella la forma natural de la mercancía A rige sola en cuanto configuración del valor de uso y que la forma natural de la mercancía $\mathrm{B}$ rige exclusivamente en cuanto forma valor o figura del valor. La contradicción que encierra la mercancía, la contradicción interna entre valor de uso y valor, se expone así en una contradicción externa, es decir, en la relación entre dos mercancías, relación dentro de la cual una de las mercancías, aquella cuyo valor se trata de expresar, sólo funciona directamente como valor de uso, mientras que la otra, aquella en que el valor se expresa, funciona directamente sólo como valor de cambio. Por tanto, la forma simple del valor de una mercancía es la forma simple de manifestarse la contradicción entre valor de uso y valor contenida en ella.

El producto del trabajo constituye un objeto de uso en toda condición social, pero sólo en una época históricamente determinada del desarrollo - la que hace aparecer el trabajo gastado en la producción de un objeto útil como una cualidad «objetiva» del mismo, es decir, como su valor - se convierte en mercancía. ${ }^{* * *}$ De donde se deduce que la forma simple del valor de la mercancía es, al mismo tiempo, la forma mercantil simple del producto del trabajo y que, por tanto, el desarrollo de esta forma mercancía coincide con el desarrollo de la forma del valor.

A primera vista se advierte ya la insuficiencia de la forma simple del valor, forma puramente embrionaria, que sólo llega a desarrollarse hasta la forma precio a través de una serie de metamorfosis.

La expresión en una mercancía в cualquiera sólo distingue el valor de una mercancía A del valor de uso de la misma; por tanto, lo que hace es únicamente ponerla en una relación de intercambio con cualquiera otra clase singular de mercancías distintas de ella, en lugar de exponer su igualdad cualitativa y su proporcionalidad cuantitativa con todas las demás mercancías. 
A la forma valor relativa simple de una mercancía corresponde la forma equivalencial singular de otra. Así, la chaqueta, en la expresión relativa del valor del lienzo, posee forma equivalencial, o sea la forma de intercambiabilidad directa, solamente con respecto a esta clase singular de mercancías que es el lienzo.

Pero la forma del valor singular transita por sí misma hasta una forma más completa. Mediante ésta, el valor de una mercancía A se limita todavía a expresarse en una mercancía de otra clase. Pero ahora es indiferente qué tipo de mercancía sea ésta: chaqueta, hierro, trigo, etc. Así pues, según qué entre en una relación de valor con ésta o la otra clase de mercancía, se forman distintas expresiones simples de valor de una y la misma mercancía. ${ }^{22 a}$ El número de sus posibles expresiones de valor sólo está limitado por el número de las clases de mercancías distintas de ella. Su expresión singularizada de valor se convierte, por tanto, en la serie permanente ampliable de sus distintas expresiones simples de valor.

\section{B) LA FORMA TOTAL O EXTENDIDA DEL VALOR}

$\mathrm{z}$ mercancía $\mathrm{A}=\mathrm{u}$ mercancía $\mathrm{B}, \mathrm{o}=\mathrm{v}$ mercancía, $\mathrm{o}=\mathrm{w}$ mercancía $\mathrm{D}, \mathrm{o}=\mathrm{x}$ mercancía $\mathrm{E}, \mathrm{o}=$ etc. ( 20 varas de lienzo $=1$ chaqueta, $o=10$ libras de té, $o=40$ libras de café, $o=1$ arroba de trigo, $o=2$ onzas de oro, $o=1 / 2$ tonelada de hierro, $o=$ etc.)

\section{LA FORMA VALOR RELATIVA: EXTENDIDA}

El valor de una mercancía, por ejemplo del lienzo, se expresa ahora en otros innumerables ejemplares del mundo de las mercancías. Todo otro cuerpo de mercancías se convierte en espejo del valor del lienzo. ${ }^{23}$ Sólo de esta manera el valor mismo aparece verdaderamente como condensación del trabajo humano indistinto. En efecto, el trabajo que lo crea se representa ahora, expresamente, como trabajo equivalente a todo otro trabajo humano, cualquiera que sea la forma natural que posee, y sea, por tanto, que se objetive como chaqueta o como trigo, como hierro o como oro, etc. Por consiguiente, gracias s esta forma de su valor, el lienzo no se halla ya en relación social sólo con otra clase singular de mercancías, sino con todo el mundo de las mercancías. Como mercancía, tienen ciudadanía en este mundo. Al mismo tiempo, la serie infinita de las expresiones de su valor lleva implícito el hecho de que al valor de la mercancía le es indiferente la forma particular del valor de uso bajo el que aparezca.

Bajo la primera forma: 20 varas de lienzo $=1$ chaqueta, el que estas dos mercancías sean intercambiables en una determinada proporción cuantitativa puede ser un hecho casual. En cambio, bajo la segunda forma se transluce inmediatamente un fondo que se distingue esencialmente de la apariencia casual y que la determina. El valor del lienzo sigue teniendo la misma magnitud, ya se exprese en la chaqueta, o en café, en hierro, etc., en innumerables y diversas mercancías, pertenecientes a los más diversos poseedores. Desaparece la relación fortuita entre dos poseedores individuales de mercancías. Se pone en evidencia que no es el intercambio lo que regula la magnitud del valor de la mercancía, sino al revés: es la magnitud del valor de la mercancía lo que regula sus relaciones proporcionales de intercambio. 


\section{LA FORMA EQUIVALENCIAL PARTICULAR}

Toda mercancía, chaqueta, té, trigo, hierro, etc. rige en la expresión de valor del lienzo como equivalente y, por lo tanto, como cuerpo-valor. La forma natural determinada de cada una de estas mercancías es, ahora, una forma equivalencial particular junto a muchas otras. Y lo mismo las múltiples clases de trabajo útil determinada, concreto, contenido en los diversos cuerpos de las mercancías: rigen ahora como otras tantas formas particulares de realización o manifestación de trabajo humano en general.

\section{DEFECTOS DE LA FORMA TOTAL O EXTENDIDA DEL VALOR}

En primer lugar, la expresión relativa del valor de la mercancía es incompleta, porque la serie de sus representaciones no se cierra nunca. La cadena en que una ecuación de valor se engarza a otra es permanentemente prolongable por medio de cualquiera nueva clase de mercancías que aparezca y suministre el material para una nueva expresión del valor. En segundo lugar, constituye un abigarrado mosaico de dispersas y diferentes expresiones de valor. Por último, si, como necesariamente tiene que ocurrir, el valor relativo de todas y cada una de las mercancías, se expresa en esta forma extendida, la forma relativa del valor de cada mercancía será una serie infinita de expresiones de su valor, diferente de la forma relativa del valor de cada una de las demás mercancías. Y los defectos de la forma valor relativa total o extendida se reflejan, a su vez, en la forma equivalencial que a ella corresponde. Como la forma natural de cada clase singular de mercancías es aquí una forma equivalencial particular junto a otras formas equivalenciales particulares innumerables, resulta que sólo existen, en general formas equivalenciales limitadas, cada una de las cuales excluye a la otra. Y, del mismo modo, la clase de trabajo útil, determinado, concreto, contenido en cada mercancía-equivalente particular, no es más que una forma particular, y por tanto no exhaustiva de manifestación del trabajo humano. Es cierto que éste posee su forma de manifestación total o completa en toda la serie de aquellas formas particulares de manifestación. Más, por ello mismo, carece de una forma unitaria de manifestación.

Pero la forma valor relativa extendida consiste únicamente en una suma de expresiones relativas simples del valor o de ecuaciones de la primera forma, tales como:

20 varas de lienzo $=1$ chaqueta

20 varas de lienzo $=10$ libras de té, etc.

Y cada una de estas ecuaciones contiene también, invertida otra ecuación idéntica:

1 chaqueta $=20$ varas de lienzo

10 libras de té $=20$ varas de lienzo, etc.

En efecto, si una persona intercambia su lienzo por otras muchas mercancías y, por tanto, expresa el valor de éste en una serie de mercancías distintas, los otros muchos poseedores de mercancías tendrán necesariamente que intercambiar sus mercancías por lienzo y, por tanto, que expresar los valores de sus distintas mercancías en la misma tercera mercancía, en lienzo.

Invirtamos, entones, la serie: 20 varas de lienzo $=1$ chaqueta, $o=10$ libras de té, $o=$ etc., es decir, hagamos expresa la relación inversa que esta serie contiene en sí misma, y tendremos: 


\section{C) LA FORMA GENERAL DEL VALOR}

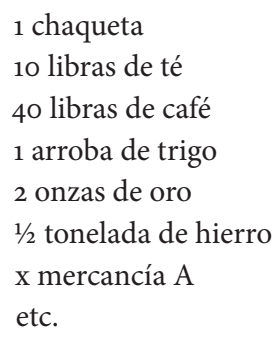

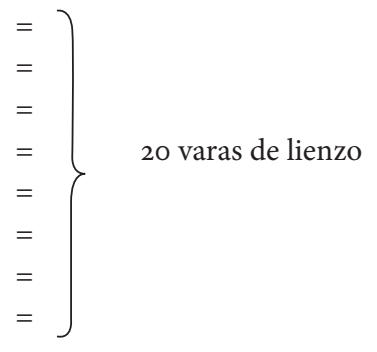

1. MODIFICACIÓN DEL CARÁCTER DE LA FORMA DEL VALOR

Las mercancías, ahora, exponen sus valores: $1^{\circ}$ de un modo simple, puesto que lo hacen en una sola mercancía y $2^{\circ}$ de un modo unitario, puesto que lo hacen en la misma mercancía. La forma de su valor es simple y colectiva, y por consiguiente general.

Las formas I y i solo alcanzaban, una y otra a expresar el valor de una mercancía como algo distinto de su propio cuerpo o valor de uso.

La primera forma conducía a ecuaciones de valor tales como: 1 chaqueta $=20$ varas de lienzo, 10 libras de té $=1 / 2$ tonelada de hierro, etc. El valor de la chaqueta se expresa aquí como algo que es igual al lienzo, el valor del té como algo que es igual al hierro, etc., pero estos dos «algos», expresiones de los valores de la chaqueta y del té, son tan distintos entre sí como las dos cosas a las que son iguales, el lienzo y el hierro. Evidentemente, esta forma solo se da, prácticamente, en los primeros inicios, allí donde un intercambio ocasional y fortuito convierte a ciertos productos del trabajo en mercancías.

La segunda forma distingue más eficazmente que la primera el valor de una mercancía del valor de uso de la mismo; en efecto, el valor de la chaqueta, por ejemplo, se enfrenta ahora a la forma natural de ésta bajo todas las formas posibles, como algo que es igual al lienzo, al hierro, al té, etc., a todo lo demás menos a la chaqueta. Pero, de otra parte, toda expresión común del valor de las mercancías queda aquí directamente excluida, ya que en la expresión del valor de cada una de ellas todas las demás mercancías aparecen sólo en forma de equivalentes. La forma del valor sólo se presenta de manera efectiva cuando un producto del trabajo, el ganado por ejemplo, es intercambiado por otras diversas mercancías, pero ya no de un modo excepcional, sino consuetudinariamente.

La nueva forma a la que llegamos expresa los valores del mundo de las mercancías en una y la misma clase de mercancías, que es aislada de ese mundo; lo hace, por ejemplo, en el lienzo, exponiendo así los valores de todas las mercancías mediante la igualdad de todos ellos con el lienzo. Como algo que es igual al lienzo, el valor de cada mercancía no sólo se distingue ahora del valor de uso, de ella sola, sino de todo valor de uso en general, precisamente por esto, es expresado como aquello que cada una de las mercancías tiene de común con todas las demás. Sólo esta forma llega, pues, a relacionar entre sí a las mercancías realmente en cuanto valores $o$ a hacer que se tengan unas a otras por valores de cambio.

Las dos formas anteriores expresan el valor de cada mercancía, ya en una sola mercancía de otra clase, ya en una serie de muchas mercancías distintas de ella. En ambos casos es, por así 
decirlo, incumbencia privada de cada mercancía al darse una forma de valor, lo que logra sin la intervención de las demás mercancías. Estas desempeñan frente a ella el papel puramente pasivo del equivalente. En cambio, la forma general del valor sólo brota como obra colectiva del mundo de las mercancías. Una mercancía sólo alcanza una expresión general de su valor, porque, al mismo tiempo, todas las otras mercancías expresan su valor en el mismo equivalente, y toda nueva clase de mercancías que surja tiene que hacer otro tanto, se hace patente así el hecho de que la objetividad de valor de las mercancías, por ser simplemente la «existencia social» de estas cosas, sólo puede expresarse también mediante su relación social ilimitada; se hace patente, por tanto, que la forma del valor debe ser una forma que tenga una vigencia social general.

Bajo la forma de ser algo que es igual al lienzo, todas las mercancías aparecen ahora, no sólo como cualitativamente iguales, como valores en general, sino al mismo tiempo, como magnitudes de valor cuantitativamente comparables. Gracias a que todas las mercancías reflejan sus magnitudes de valor en un mismo material, en lienzo, toda magnitud de valor se ve reflejada en cada una de las demás. Por ejemplo, 10 libras de té $=20$ varas de lienzo y 40 libras de café $=20$ varas de lienzo. Por tanto, 10 libras de té $=40$ libras de café o, lo que es igual, en 1 libra de café se contiene solamente $1 / 4$ de sustancia de valor, de trabajo, de lo que se encierra en 1 libra de té.

La forma valor relativa general del mundo de las mercancías imprime a la mercancía equivalente excluida de él, al lienzo, el carácter del equivalente general. La propia forma natural de éste es la configuración común del valor de ese mundo de las mercancías; el lienzo es, por tanto, directamente intercambiable por cualquier otra mercancía. Su forma corpórea es considerada como la encarnación visible, la representación social general de todo trabajo humano. El trabajo textil, el trabajo privado que produce el lienzo, se encuentra además en forma social-general, en la forma de la igualdad con todos los otros trabajos. Las innumerables ecuaciones en que consiste la forma general del valor van equiparando por turno el trabajo materializado en el lienzo al trabajo contenido en cualquier otra mercancía, convirtiendo con ello al trabajo textil en la forma general de manifestación de todo trabajo humano. De este modo, el trabajo objetivado en el valor de las mercancías no se halla representado solamente, de un modo negativo, como trabajo en que se hace abstracción de todas las formas concretas y todas las cualidades, útiles de los trabajos reales.

Se destaca expresamente su propia naturaleza positiva: la reducción de todos los trabajos reales al carácter, común a todos ellos, de trabajo humano, de gasto de fuerza de trabajo humana.

La forma general del valor, que expone a los productos del trabajo como simples condensaciones de trabajo humano indistinto, muestra por su propia estructura que es la expresión social del mundo de las mercancías. Revela así que, dentro de este mundo, el carácter social del trabajo se constituye específicamente como carácter humano general.

\section{RELACIÓN ENTRE EL DESARROLLO DE LA FORMA VALOR RELATIVA Y EL DE LA FORMA EQUIVALENCIAL}

Al grado de desarrollo de la forma valor relativa corresponde el grado de desarrollo de la forma equivalencial. Pero - y esto es conveniente subrayar - el desarrollo de la forma equivalencial es solamente expresión y resultado del desarrollo de la forma valor relativa. 
La forma valor relativa simple o singular de una mercancía hace de otra su equivalen-te individual. La forma extendida del valor relativo, que expresa el valor de una mercancía en todas las demás, imprime a éstas la forma de equivalentes particulares de distinta clase. Por último, una clase especial de mercancías adquiere la forma general de equivalente, porque todas las otras las convierte en material de la forma general y unitaria de su valor.

Pero, al mismo grado en que se desarrolla en general la forma del valor, se desarrolla también la antítesis entre sus dos polos: la forma valor relativa y la forma equivalencial.

Ya la primera forma -20 varas de lienzo $=1$ chaqueta - implica esta antítesis aunque sin darle un carácter fijo. Según que esta ecuación se lea hacia adelante o hacia atrás, cada una de las dos mercancías que forman los términos de la ecuación, el lienzo y la chaqueta, aparece una vez con la forma valor relativa y otra con la forma de equivalente. Aquí resulta difícil todavía retener la antítesis polar.

Bajo la forma II, es siempre sólo una clase de mercancías la que puede en cada caso extender totalmente su valor relativo; o lo que es lo mismo, ella posee la forma valor relativa extendida solo en virtud y en la medida en que todas las mercancías se encuentran frente a ella en la forma equivalencial. Aquí ya no es posible invertir los dos términos de la ecuación, de valor - como 20 varas de lienzo $=1$ chaqueta, $\mathrm{o}=10$ libras de té, o 1 arroba de trigo, etc. - sin hacer cambiar todo su carácter y convertirla de forma total en forma general del valor.

La última forma, la forma III, infunde finalmente al mundo de las mercancías la forma valor relativa social-general en virtud y en la medida en que, con una sola excepción, todas las mercancías pertenecientes a él quedan excluidas de la forma equivalencial general. Aquí, por tanto, una mercancía, el lienzo, reviste la forma de la intercambiabilidad directa por todas las demás, o se presenta en forma directa social, en virtud y en la medida en que todas las otras mercancías no revisten dicha forma. ${ }^{24}$

Y, a la inversa, la mercancía que figura como equivalente general es excluida de la forma valor relativa unitaria, y por tanto general, del mundo de las mercancías. Para que el lienzo, es decir, cualquier mercancía que se encuentre en forma equivalencial general, pudiera participar al mismo tiempo de la forma valor relativa general, tendría que servirse a sí misma como equivalente. Y tendríamos entonces: 20 varas de lienzo $=20$ varas de lienzo, tautología que no expresa ni valor ni magnitud de valor. Para expresar el valor relativo del equivalente general, tenemos más bien que invertir la forma III. La forma valor relativa del equivalente general no tiene nada en común con la de las demás mercancías; su valor, se expresa relativamente en la serie infinita de todos los demás cuerpos de las mercancías. Por donde la forma valor relativa extendida, o forma II, se revela ahora como la forma valor relativa específica de la mercancía-equivalente.

\section{TRANSICIÓN DE LA FORMA GENERAL DEL VALOR A SU FORMA GENERAL EN DINERO}

La forma equivalencial general es, en general, una forma del valor. Puede, por tanto, corresponderle a cualquier mercancía. Mas, por otra parte, una mercancía solo reviste la forma equivalencial general - la forma III - en virtud y en la medida en que es excluida como equivalente por todas las demás mercancías. Y, solo a partir del momento en que esta exclusión se circunscribe definitivamente a una clase especifica de mercancías, la forma valor relativa unitaria del mundo de las mercancías adquiere firmeza objetiva y cobra vigencia social general. 
Ahora bien, la clase especifica de mercancías con cuya forma natural se interpenetra socialmente la forma equivalencial se convierte en una mercancía-dinero o funciona como dinero. El desempeñar dentro del mundo de las mercancías el papel de equivalente general se convierte en su función social específica y, por tanto, en su monopolio social. Este lugar de preferencia lo ha conquistado históricamente entre las mercancías que en la forma in figuran como equivalentes particulares de lienzo y que en las forma iII expresan conjuntamente su valor relativo en el lienzo, una determinada mercancía: el oro. Así pues, si en la forma III sustituimos la mercancía lienzo por la mercancía oro, obtendremos:

\section{D) LA FORMA GENERAL DEL VALOR: EN DINERO ${ }^{* * * * * * * *}$}

$\left.\begin{array}{ll}20 \text { varas de lienzo } & = \\ 1 \text { chaqueta } & = \\ 10 \text { libras de té } & = \\ 40 \text { libras de café } & = \\ 1 \text { arroba de trigo } & = \\ \begin{array}{l}1 / 2 \text { tonelada de hierro } \\ \mathrm{x} \text { mercancía } \mathrm{A}\end{array} & =\end{array}\right\} 2$ onzas de oro

En el paso de la forma i a la forma iI y de la forma iI a la forma iII se producen modificaciones esenciales. En cambio, la forma iv en nada se distingue de la forma iII, salvo por el hecho de que la forma de equivalente general pertenece ahora al oro, en vez de al lienzo. En la forma IV, el oro sigue siendo lo que en la forma in era el lienzo: equivalente general. El único progreso consiste en que la forma de la intercambiabilidad general y directa o la forma equivalencial general se encuentra ahora, en virtud de la costumbre social, entretejida definitivamente, con la forma natural específica de la mercancía oro.

El oro solo se enfrenta a las demás mercancías como dinero porque ya antes estaba frente a ellas como mercancía. Funcionaba ya, al igual que todas las demás mercancías, también como equivalente, sea como equivalente singular en actos de intercambio aislados, sea como equivalente particular junto a otras mercancías equivalentes. Poco a poco, en círculos más restringidos o más amplios, fue funcionando como equivalente general. Tan pronto como llega a conquistar el monopolio de esta función en la expresión del valor del mundo de las mercancías, se convierte en la mercancía-dinero, y solo a partir de este momento, cuando el oro se ha vuelto ya dinero, la forma IV se distingue de la forma III o la forma general del valor se convierte en forma [del valor] en dinero.

La expresión relativa simple del valor de una mercancía, por ejemplo, del lienzo, realizada en la mercancía que funciona ya como mercancía dinero, por ejemplo en el oro, es su expresión en forma de precio. Por tanto, la «forma de precio» para el lienzo será:

20 varas de lienzo $=2$ onzas de oro

o, si 2 lbs. esterlinas es el nombre monetario de 2 onzas de oro,

20 varas de lienzo $=2$ lbs. esterlinas. 
En el concepto de la forma [del valor] en dinero, la dificultad está únicamente en captar conceptualmente la forma equivalencial general, en definitiva, la forma general del valor, la forma III. La cual, en sentido retrospectivo, se reduce a la forma II, a la forma extendida del valor, cuyo elemento constituyente es al forma $\mathrm{I}$ : 20 varas de lienzo $=1$ chaqueta $\mathrm{o}$ x mercancía $\mathrm{A}$ = у mercancía в. La simple forma mercancía — del producto- es, por tanto, el germen de la forma - del valor- en dinero.

\section{EL CARÁCTER FETICHE QUE TIENE LA MERCANCÍA, Y SU SECRETO}

A primera vista, una mercancía parece una cosa trivial, que no plantea ningún problema. Pero de su análisis resulta que es algo muy intrincado, lleno de sutilezas metafísicas y de caprichos teológicos. En tanto que valor de uso, no hay en ella nada de misterioso, sea que la consideremos como algo que por sus cualidades satisface ciertas necesidades humanas o como algo que sólo adquiere esas cualidades al ser producto del trabajo humano. Es claro como la luz del día, que el hombre, por medio de su actividad, modifica de un modo útil para él las formas de las materias naturales. La forma de la madera, por ejemplo, cambia al hacer de ella una mesa. No obstante lo cual, la mesa sigue siendo madera, un objeto sensible como otro cualquiera. En cambio, en cuanto se presenta como mercancía, se transforma en una cosa sensible y a la vez suprasensible. No sólo descansa con sus patas sobre el suelo, sino que se pone de cabeza frente a las demás mercancías, y de su cabeza de palo comienza a soltar extravagantes ocurrencias, muchos más asombrosas que si de pronto ella, por sí misma, se pusiese a bailar. ${ }^{25}$

El carácter místico de la mercancía no brota, entonces de su valor de uso. Ni brota tampoco del contenido de las determinaciones del valor. Puesto que, en primer lugar, por muy diferentes que sean los trabajos útiles o las actividades productivas, es una verdad fisiológica que son funciones del organismo humano y que cada una de estas funciones cualesquiera que su contenido y forma sean, constituyen esencialmente un gasto de los órganos sensoriales y los músculos del hombre, de sus nervios, su cerebro, etc. En segundo lugar, respecto de lo que sirve de base para determinar la magnitud del valor —es decir, la duración en el tiempo de aquel gasto o la cantidad de trabajo - la cantidad puede ser distinguida incluso tangiblemente de la calidad del trabajo. El tiempo de trabajo que al hombre le cuesta producir sus medios de vida es algo que tuvo que interesarle necesariamente en todas las situaciones, aunque no por igual en las diferentes fases de su desarrollo. ${ }^{26}$ Por último, tan pronto como los hombres trabajan de algún modo los unos para los otros, su trabajo cobra también una forma social.

¿De dónde emana, pues, el carácter misterioso del producto del trabajo, en cuanto adopta la forma mercancía? Sólo puede emanar, evidentemente, de esta forma misma. La igualdad de los trabajos humanos recibe la forma cósica de objetividad igual del valor de los productos del trabajo; la medida del gasto de fuerza de trabajo humana según el tiempo de su duración reviste la forma de magnitud del valor de los productos del trabajo; finalmente, las relaciones entre los productores, en las que se efectúan aquellas determinaciones sociales de sus trabajos, cobran la forma de una relación social entre los productos del trabajo.

Lo que hay de misterioso en la forma mercancía reside, pues, simplemente en que refleja ante los hombres el carácter social del propio trabajo de éstos como carácter objetivo de los mismos productos del trabajo, como cualidad social propia de la naturaleza de estas mismas 
cosas; por tanto, en que refleja también la relación social de los productores con el trabajo de todos como una relación social existente en exterioridad a ellos, entre los objetos. Este quid pro quo [sustitución] es lo que hace de los productos del trabajo mercancías, objetos sensibles y suprasensibles a un tiempo, objetos sociales. Es como la impresión luminosa de una cosa sobre el nervio óptico que se presenta como forma objetiva [gegenständlich], exterior al ojo, propia de esa cosa, y no como lo que ella realmente es: una excitación subjetiva del mismo nervio óptico. Pero en el caso de la visión hay realmente una cosa, el objeto exterior que proyecta luz sobre el ojo. Se trata de una relación física entre objetos físicos. En cambio, la forma mercancía y la relación de valor de los productos del trabajo, en la que ella se pone de manifiesto, no tiene absolutamente nada que ver con su naturaleza física ni con las relaciones materiales nacidas de ella. Lo que adopta aquí para los hombres, la forma fantasmagórica de una relación entre cosas no es más que la propia relación social determinada que media entre ellos mismos. Para encontrar una analogía debemos por tanto, recurrir a la nebulosa esfera del mundo religioso. En él, los productos de la cabeza humana aparecen como figuras independientes y dotadas de vida propia, que se relacionan entre sí y con los hombres. Lo mismo ocurre, en el mundo de las mercancías, con los productos de la mano del hombre. Es lo que yo lo llamo el carácter de fetiche, que se adhiere a los productos del trabajo en cuanto son producidos como mercancías y que es, por tanto, inseparable de la producción mercantil.

Este carácter de fetiche del mundo de las mercancías brota, como ha revelado ya el precedente análisis, del peculiar carácter social del trabajo productor de mercancías.

Los objetos de uso sólo se convierten en mercancías porque son productores de trabajos privados, independientes los unos con los otros. El conjunto complejo de estos trabajos privados constituye el trabajo total de la sociedad. Y, como los productores sólo entran en contacto social mediante el intercambio de los productores de su trabajo, también los caracteres específicamente sociales de sus trabajos privados aparecen sólo dentro de este intercambio. $\mathrm{O}$, lo que es lo mismo, los trabajos privados sólo se comportan, en realidad, como miembros del trabajo social total en virtud de las relaciones que el intercambio impone a los productos del trabajo y, por su intermedio, a los mismos productores. Por ello, ante éstos, las relaciones sociales entre los trabajos privados aparecen como lo que son, es decir, no como relaciones inmediatamente sociales entre personas en sus trabajos mismos, sino como relaciones cósicas entre personas y relaciones sociales entre cosas.

Es sólo dentro de su intercambio cuando los productos del trabajo cobran una objetividad socialmente igual de valor, aparte de su objetividad de uso sensiblemente diferenciada. Esta escisión del producto del trabajo en cosa útil y cosa de valor sólo se efectúa prácticamente cuando el intercambio ha adquirido ya la extensión y la importancia suficientes como para que ciertas cosas útiles se produzcan con el fin de ser intercambiadas, es decir, cuando el carácter de valor de las cosas se toma en cuenta ya en su producción misma. A partir de este momento, los trabajados privados de los productores cobran de hecho un doble carácter social. De una parte, en cuanto trabajos útiles determinados, tienen que satisfacer una determinada necesidad social y afirmarse, por tanto, como miembros del trabajo total, del sistema naturalmente dado, de la división social del trabajo. Y, de otra parte, sólo satisfacen las múltiples necesidades de sus propios productores en la medida en que cada particular trabajo útil es 
intercambiable por cualquier otro trabajo privado útil y rige, por tanto, como igual a él. Ahora bien, la igualdad entre trabajos toto caelo [a todas luces] distintos sólo puede consistir en una abstracción de su igualdad real, en la reducción de todos ellos al carácter común que poseen en cuanto gasto de fuerza de trabajo humana, en cuanto trabajo humano abstracto. La mente de los productores privados no hace más que reflejar este doble carácter social de sus trabajos privados bajo las formas que aparecen en su convivencia práctica, en el intercambio de productos: el carácter socialmente útil de sus trabajos privados, bajo la forma de que el producto del trabajo tiene que ser útil, y útil para otros; el carácter social de la igualdad entre los diferentes trabajos, bajo la forma del carácter común de valor de estas cosas materialmente distintas, los productos del trabajo.

Por consiguiente, los hombres no ponen en relación como valores a los productos de sus trabajos por que estas cosas consistan para ellos en simples envolturas cósicas, de trabajo humano del mismo tipo. A la inversa, es al equiparar entre sí sus diferentes productos como valores en intercambio, que igualan entre sí a sus distintos trabajos en tanto, que trabajo humano. No lo saben, pero lo hacen. ${ }^{27}$ El valor, por tanto, no lleva escritorio en la frente lo que es. Lejos de ello, el valor convierte todo producto del trabajo en un jeroglífico social. Más tarde, los hombres tratan de descifrar el jeroglífico, de descubrir el misterio de su propio producto social, pues la determinación de los objetos de uso como valores es un producto social suyo, ni más ni menos que lo es el lenguaje. Y después, aunque el descubrimiento científico de aquellos productos del trabajo, en cuanto valores, son meras expresiones cósicas del trabajo humano gastada en su producción hace época en la historia de desarrollo de la humanidad, no disipa sin embargo la apariencia cósica del carácter social del trabajo. Lo que sólo tiene vigencia en esta forma particular de producción, en la producción de mercancías - a saber: el hecho de que el carácter social específico de los trabajos privados independientes unos de otros consiste en que todos ellos son iguales en cuanto trabajo humano, y de que este carácter adopta la forma de carácter de valor de los productos del trabajo - se presenta, para quienes se encuentran atrapados en las relaciones de la producción de mercancías, y los mismo antes que después de dicho descubrimiento, como si fuera algo tan definitivo como lo es la forma aire, en tanto que forma de un cuerpo físico, que subsiste después de la desintegración científica del aire en sus elementos.

Lo que ante todo interesa prácticamente a quienes intercambian sus productos es saber cuántos productos ajenos recibirán por el suyo, es decir, en qué proporción pueden intercambiarlos. Cuando estas proporciones llegan a adquirir cierta firmeza consuetudinaria, dan la apariencia de brotar de la naturaleza misma de los productos del trabajo; así, por ejemplo, una tonelada de hierro y 2 onzas de oro parecen tener, por su propia virtud, el mismo valor, a la manera como una libra de oro y una libra de hierro tiene el mismo peso [Schwere] aunque poseen cualidades físicas y químicas diferentes. En realidad, el carácter de valor de los productos del trabajo sólo adquiere fijeza cuando estos productos actúan ya como magnitudes de valor. Estas cambian constantemente, al margen de la voluntad, el conocimiento previo y el hacer de quienes participan en el intercambio. Para ello, su propio movimiento social posee la forma de un movimiento de cosas; cosas que los gobiernan, en vez de ser gobernadas por ellos. Y es necesario que la producción de mercancías llegue a desarrollarse plenamente para que, de la experiencia misma, brote la idea [Einsicht] científica de que los trabajos privados - que se ejercen 
independientemente los unos de los otros, pero que son interdependientes en todo sentido, como miembros naturalmente dados de la división social del trabajo- son reducidos constantemente a su medida socialmente proporcional debido a que, en las relaciones fortuitas y siempre oscilantes de intercambio de sus productos, el tiempo de trabajo socialmente necesario para su producción se impone a la fuerza, como una ley natural reguladora, a la manera como se impone, digamos, la ley de la gravedad, cuando a uno le cae la casa encima. ${ }^{28} \mathrm{La}$ determinación de la magnitud de valor por el tiempo de trabajo constituye, por tanto, un misterio oculto bajo los movimientos fenoménicos de los valores relativos de las mercancías. Su descubrimiento suprime la apariencia de la determinación puramente fortuita de las magnitudes de valor de los productos del trabajo, pero no destruye en modo alguno su forma cósica.

La reflexión acerca de las formas de la vida humana y también por tanto, su análisis científico sigue en general un camino opuesto al desarrollo real. Se inicia post festum [después de lo ocurrido] y parte, por consiguiente, de los resultados ya determinados del proceso de desarrollo. Las formas que configuran a los productos del trabajo como mercancías, y que se encuentran por tanto, presupuestas en la circulación de mercancías, han llegado ya a poseer la firmeza de formas naturales de la vida social, antes de que los hombres comiencen a tratar de explicárselas - y no en busca de su carácter histórico-, pues las consideran ya inmutables, sino de su contenido. Fue así que sólo el análisis de los precios de las mercancías llevó a la determinación de la magnitud del valor; es decir, sólo la expresión colectiva de las mercancías en el dinero condujo a establecer su carácter de valor. Pero es precisamente esta forma acabada del mundo de las mercancías - la forma de dinero- la que, en vez de poner de manifiesto, vela bajo el manto de una cosa el carácter social de los trabajos privados y, por consiguiente, las relaciones sociales entre los trabajadores privados. Cuando digo que la chaqueta, las botas, etc. se refieren al lienzo en tanto que materialización general del trabajo humano abstracto, en seguida salta a la vista lo absurdo [Verrückcheit] de esta expresión. Ahora bien, cuando los productores de chaquetas, botas, etc., refieren estas mercancías al lienzo - o al oro y la plata, lo que no latera para nada el asunto- como equivalente general, es la relación de sus trabajos privados con el total de la sociedad la que aparece ante ellos precisamente bajo esta forma absurda.

Formas como esta, son justamente las que constituyen las categorías de la economía burguesa. Son formas conceptuales socialmente válidas, y por tanto objetivas dentro de las relaciones de producción de este modo social de producción históricamente determinado, el de la producción de mercancías. De ahí que todo el misticismo del mundo de las mercancías, todos los encantamientos y apariciones que envuelven a los productos del trabajo, cuando existen sobre la base de la producción de mercancías, desaparezcan inmediatamente tan pronto como escapamos a otras formas de producción.

Como la economía política gusta de las robinsonadas, ${ }^{29}$ representémonos, en primer lugar, a Robinson en su isla. Robinson, aún siendo como es de por sí un hombre sobrio, tiene diferentes necesidades que satisfacer y ello le obliga a realizar trabajos útiles de diversas clases, tales como fabricar instrumentos, construir muebles, domar animales, pescar, cazar, etc. Y no hablamos de rezar y otras actividades similares, pues nuestro Robinson encuentra en ellas un placer y las cuenta más bien como entretenimientos. Por muy diversas que sus actividades productivas sean, Robinson sabe perfectamente que no son más que diferentes modos suyos 
de ponerse en acción, es decir, diversas modalidades del trabajo humano. Es la misma necesidad la que le obliga a dividir exactamente su tiempo entre sus diversas funciones. El que una ocupe un espacio mayor y otra uno menor dentro de su actividad total, dependerá de la mayor o menor dificultad que tenga que vencer en cada caso para alcanzar el efecto útil perseguido en ellas. La experiencia se lo enseña así, y nuestro Robinson, que ha salvado del naufragio el reloj, el libro de cuentas, tinta y pluma, comienza, como buen inglés, levantando un inventario acerca de sí mismo. En él figura una relación de los objetos útiles que posee, de las diferentes operaciones de los objetos útiles que posee, de las diferentes operaciones necesarias para producirlos y, finalmente, del tiempo de trabajo que, por término medio, le cuestan determinadas cantidades de estos diferentes productos. Todas las relaciones entre Robinson y las cosas que forman la riqueza creada por él son tan simples y transparentes que hasta el señor M. Wirth podría comprenderlas sin grandes quebraderos de cabeza. Y, sin embargo, se contienen en ellas todas las determinaciones esenciales del valor.

Trasladémonos ahora de la luminosa isla de Robinson a la sombría Edad Media. En vez del hombre independiente, encontramos aquí que todos son dependientes: siervos y señores feudales, vasallos y patrones, clérigos y seglares. La dependencia personal caracteriza aquí tanto las relaciones sociales de la producción material como las esferas de la vida erigidas sobre ellas. Pero, precisamente porque las relaciones personales de dependencia forman la base social dada, los trabajos y sus productos no necesitan adoptar una forma fantástica, diferente de su realidad. Entran en el mecanismo social como servicios naturales y prestaciones naturales. Es la forma natural del trabajo, su especificidad, y no, como en la producción de mercancías, su generalidad, lo que constituye aquí directamente su forma social. El trabajo servil se mide por el tiempo, ni más ni menos que el trabajo productor de mercancías, pero todo siervo sabe que es una determinada cantidad de su fuerza personal de trabajo la que rinde al servicio de su señor. El diezmo que debe pagar al cura es más evidente que la bendición que el cura imparte. Por tanto, como quiera que se juzguen las máscaras escénicas con que los hombres se enfrentan aquí los unos a los otros, las relaciones sociales entre las personas, en sus trabajos, se manifiestan, en todo caso, como sus propias relaciones personales, y no aparecen revestidas bajo el manto de relaciones sociales entre las cosas, entre los productos del trabajo.

Para considerar el trabajo en común, es decir, el trabajo directamente socializado, no necesitamos remontarnos a la forma naturalmente dada del mismo, que encontramos en el umbral histórico de todos los pueblos civilizados..$^{30}$ Un ejemplo más al alcance de la mano nos lo ofrece la industria patriarcal rural de una familia campesina que produce trigo, ganado, hilaza, lienzo, piezas de vestir, etc., para el propio consumo. Estos diferentes objetos están frente a la familia en tanto que productos del trabajo familiar diferenciado, pero no están ellos mismos unos frente a otros como mercancías. Los diferentes trabajos de los que provienen estos productos: la agricultura, la ganadería, el trabajo de hilar y tejer, el de sastrería, etc., son, bajo su forma natural, funciones sociales, por ser funciones de la familia, la cual posee dada naturalmente su propia división del trabajo, ni más ni menos que la producción de mercancías. Las diferencias de sexo y edad, así como las condiciones naturales de trabajo, que cambian al cambiar las épocas del año, regulan la distribución del trabajo en el seno de la familia y el tiempo de trabajo de los distintos miembros de esta. Y si el gasto de las fuerzas individuales de trabajo, 
medida por su duración en el tiempo, aparece aquí, de por sí, como la determinación social de los trabajos mismos, ello se debe a que las fuerzas individuales de trabajo actúan, acordes con su consistencia original, sólo como órganos de la fuerza común de trabajo de la familia.

Por último, para variar, imaginémonos una asociación de hombres libres, que trabajan con medios de producción comunes y que, con autoconciencia, emplean sus muchas fuerzas de trabajo individuales como una sola fuerza de trabajo social. Volvamos a encontrarnos aquí con todas las determinaciones del trabajo robinsoniano, pero ahora con carácter social y no individual. Todos los productos de Robinson eran su exclusivo producto personal y, por tanto, objetos directos de uso para él. El producto total de la asociación a que nos referimos es un producto social. Una parte de este producto sirve, a su vez, de medio de producción. Sigue siendo social. Otra parte es consumida por los miembros de la asociación en forma de medios de vida. Tienen, por tanto, que ser distribuida entre ellos. El tipo de distribución variará según el tipo particular del propio organismo social de la producción y el correspondiente nivel histórico de desarrollo de los productores. Presupongamos, solamente a modo de paralelo con la producción de mercancías, que la porción de los medios de vida que corresponde a cada productor se determine por el tiempo de trabajo de éste. El tiempo de trabajo desempeñaría, según esto, un doble papel. Su distribución socialmente planificada regularía las justas proporciones entre las distintas funciones del trabajo y las distintas necesidades. Y, de otra parte, el tiempo de trabajo serviría, a la vez, como medida de la participación individual del productor en el trabajo común y también, por tanto, en la parte del producto común destinada al consumo individual. Las relaciones sociales de los hombres con sus trabajos y con sus productos permanecen aquí perfectamente simples y claras, tanto en lo tocante a la producción como en lo que se refiere a la distribución.

El cristianismo, con su culto del hombre abstracto sobre todo en el desarrollo burgués de esta religión, el protestantismo, el deísmo, etc., es la forma de religión más adecuada para una sociedad de productores de mercancías, cuya relación social general de producción consiste en comportarse hacia sus productos como hacia mercancías, es decir, hacia valores, y en relacionar entre sí sus trabajos privados, bajo esa misma forma cósica, en calidad de trabajo humano igual. En el modo de producción de la vieja Asia, en el de la Antigüedad, etc., la transformación del producto en mercancía, y por tanto, la existencia del hombre como productor de mercancías, desempeña un papel secundario, que tiende sin embargo a acentuarse a medida que la comunidad entra en su fase de decadencia. Verdaderos pueblos comerciales sólo existen en los intermundios del antiguo orbe, como los dioses de Epicuro o como los judíos en los poros de la sociedad polaca. Aquellos viejos orgánicos sociales de producción son extraordinariamente más simples y más claros que la sociedad burguesa, pero, tienen como base, o bien la inmadurez del hombre individual, que aún no ha roto el cordón umbilical de su entrelazamiento genérico natural con otros, o bien relaciones directas de señorío y servidumbre. Se hallan condicionados por un bajo nivel de desarrollo de las fuerzas productivas del trabajo y por la correspondiente sujeción de las relaciones humanas - es decir, de los hombres entre sí y con la naturaleza - a los límites del proceso material de creación de vida. Esta sujeción real se refleja idealmente en las viejas religiones naturales y populares. En general. El reflejo religioso del mundo real sólo podrá desaparecer cuando las relaciones de la vida práctica de 
trabajo representen para los hombres, cotidianamente, relaciones racionales y comprensibles [durchsichtig vernünftige] entre sí y con la naturaleza. La configuración del proceso social de vida, es decir, del proceso material de producción, sólo se despojará de su nebuloso velo místico desde el momento en que se halle, como producto de hombres libremente socializados, bajo el gobierno consciente y planificado de ellos. Para esto se requiere, sin embargo, una base material de la sociedad o una serie de condiciones materiales de existencia, las que, a su vez, son el producto naturalmente dado de una larga y dolorosa historia de desarrollo.

Es cierto que la economía política, aunque de un modo imperfecto, ${ }^{31}$ ha analizado el valor y la magnitud de valor y descubierto el contenido que se esconde bajo estas formas. Pero jamás ha llegado siquiera a plantearse la pregunta: ¿por qué este contenido adopta aquella forma, es decir, por qué el trabajo se manifiesta en el valor y la medida del trabajo según su duración se

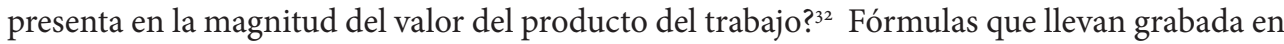
la frente su pertenencia a una formación social en la que el proceso de producción domina a los hombres y el hombre no manda aún sobre el proceso de producción, pasan por ser, ante su conciencia burguesa, una necesidad natural tan evidente como el trabajo productivo mismo. Es así que las formas preburguesas del organismo social de producción son tratadas por ello del modo como los Padres de la Iglesia trataban a las religiones precristianas. ${ }^{33}$

Hasta qué punto una parte de los economistas se dejan engañar por el fetichismo ad-herido al mundo de las mercancías, o apariencia objetiva de las determinaciones sociales del trabajo, lo demuestra, entre otras cosas, esa disputa tan aburrida y absurda en torno al papel de la naturaleza en la formación del valor de cambio. El valor de cambio es una manera social determinada de expresar el trabajo empleado en una cosa, razón por la cual no puede contenerse en él más materia natural de la que se contiene, por ejemplo, en la cotización de una divisa monetaria.

Como la forma mercancía es la forma más general y menos desarrollada de la producción burguesa -razón por la cual aparece desde muy temprano, aunque no del mismo modo dominante, es decir, característico, como hoy en día- parece todavía relativamente fácil mirar a través [durchschauven] de su carácter de fetiche. Bajo formas más concretas, incluso esta apariencia de sencillez desaparece. ¿A qué se debe, si no, las ilusiones del sistema monetario? Este no se percató de que el oro y la plata, en cuanto dinero, representan una relación social de producción, sólo que bajo la forma de cosas naturales, dotadas de cualidades sociales especiales. Y la moderna economía, que mira por encima del hombre al sistema monetario, ¿acaso no revela de un modo tangible su fetichismo, tan pronto como se da al estudio del capital? ¿Cuánto tiempo hace que desapareció la ilusión fisiocrática de que la renta del suelo brota de la tierra, y no de la sociedad?

Pero, para no adelantarnos, bastará con que pongamos aquí un ejemplo en relación con la misma forma mercancía. Si las mercancías pudieran hablar, dirían: A los hombres puede interesarles nuestro valor de uso. Pero éste no nos es inherente en cuanto cosas. Lo que sí nos es inherente en cuanto tales es nuestro valor. Así lo demuestran nuestras propias relaciones como cosas-mercancías. Sólo como valores de cambio nos referimos las unas a las otras. Escuchemos ahora como se expresa el economista, hablando desde el alma de las mercancías:

«El valor» (valor de cambio) «es una cualidad de las cosas, la riqueza» (el valor de uso) «lo es del hombre. El valor, así entendido, implica necesariamente el intercambio, la riqueza no». ${ }^{34}$ 
«La riqueza» (el valor de uso) «es un atributo del hombre, el valor un atributo de las mercancías. Un hombre o una comunidad son ricos; una perla o un diamante son valiosos... una perla o un diamante tienen valor como perla o como diamante». ${ }^{55}$

Hasta ahora, ningún químico ha descubierto el valor de cambio en una perla o un diamante. Pero los economistas descubridores de esta sustancia química, con todas sus pretensiones de profundidad crítica, consideran que el valor de uso de las cosas es independiente de sus cualidades materiales, mientras que el valor es inherente a ellas como tales cosas. Lo que les reafirma en esta opinión es el hecho curioso de que el valor de uso de las cosas se realiza para los hombres sin el intercambio, es decir, en la realización inmediata entre el hombre y la cosa, mientras que el valor se realiza solamente en el intercambio, es decir, en un proceso social. ¿Quién no recuerda, al oír esto, al buen Dogberry cuando, aleccionando a Seacoal, el sereno, le decía: «Ser un hombre bien parecido es un don de las circunstancias; el saber leer y escribir es lo que viene por naturaleza». ${ }^{36}$

\section{NOTAS}

1 C. Marx, Zur Kritik der Politischen Oekonomie [«Contribución a la crítica de la economía política»], Berlín 1859, pág. 3.

2 «La apetencia implica necesidad; es el apetito del espíritu y algo tan natural como lo es el hambre para el cuerpo... La mayoría (de las cosas) tienen un valor por que satisfacen las necesidades del espíritu». (Nicholas Barbon, A Discourse concerning coining the new money lighter. In answer to Mr. Locke's Considerations etc. [«Discurso sobre la acuñación más ligera de la moneda. Respuesta a las Consideraciones etc. de Mr. Locke»], Londres 1696, págs. 2 s.).

3 «Las cosas tienen una virtud intrínseca» (Vertue, tal es el término específico empleado por Barbon para designar el valor de uso), «que es siempre la misma, como la virtud del imán de atraer al hierro» (I.c., pág. 6). Pero esta cualidad del imán sólo se reveló como útil a partir del momento en que ayudó a descubrir la polaridad magnética.

4 «El valor natural (natural worth) de una cosa consiste en la aptitud que tiene para satisfacer las necesidades o servir a las comodidades de la vida del hombre» (John Locke, Some Considerations on the Consequences of the Loweing of Interrest [«Algunas consideraciones sobre las consecuencias de reducir el interés»] 1691, en Works («Obras»), ed. Londres 1777, t. II pág. 28). En el siglo XVII, era frecuentemente que los autores ingleses emplearan todavía la palabra «worth» para designar el valor de uso y «value» para denotar el valor de cambio, como corresponde al espíritu de una lengua que gusta de expresar el objeto inmediato con una palabra germánica y el objeto de reflexión con un término latino.

5 En la sociedad civil reina la fictio juris (ficción jurídica) de que toda persona, en tanto comprador de mercancías, posee un conocimiento enciclopédico acerca de éstas.

6 «El valor consiste en la relación de cambio que media entre dos cosas, entre una porción de un producto y otra de otro» (Le Trosne, De L'Intéret Social, [en] «Physiocrates», ed. Daire, París 1846, pág. 889). 7 «Nada puede tener un valor de cambio interno» (N. Barbon, I.c. pág. 6) o, como dice Butler: «El valor de una cosa es exactamente igual a lo que habrá de aportar».

8 "One sort of wares are as good as another, if the value be equal. There is no difference or distinction in things of equal value... One hundred pounds worth of lead or iron, is as great a value as one hundred pounds worth of silver and gold». [«...Plomo o hierro por un valor de cien $£$ tienen el mismo valor de cambio que plata u oro por un valor de cien £»] (N. Barbon, I.c. págs. 53 y 7).

9 Nota a la 2. ${ }^{a}$ ed.: "The value of them (the nedessaries of life) when they are exchanged the one for another, is regulated by the quantity of labour necessarily required, and commonly taken in producing them». [«El valor de los objetos de uso, cuando se intercambian unos por otros, se determina por la cantidad de trabajo requerido necesariamente y empleado ordinariamente en su producción»]. Some Thoughts on 
the Interest of Money in general, and particulary in the Public Funds, etc. ["Algunas ideas sobre el interés del dinero en general, y en especial en los fondos públicos, etc.»]. Londres, págs. 36 s.). Esta curiosa obra anónima del siglo pasado no tiene fecha, pero de su contenido se infiere que debió publicarse durante el reinado de Jorge II, hacia 1739 o 1740.

10 «Todos los productos de la misma clase forman en rigor una sola masa, cuyo precio se determina con carácter general y sin atender a las circunstancias particulares». (Le Trosne, I.c., pág. 893).

11 C. Marx, I.c., pág. 6.

11a (Nota a la 4. ${ }^{\text {a }}$ ed.: Intercalo lo que figura entre corchetes porque el no tenerlo en cuenta conduce frecuentemente al malentendido según el cual Marx consideraría como mercancía todo producto consumido por otro que no sea el productor, F. E.).

12 C. Marx, I.c., págs. 12, 13 y passim.

13 «En todos los fenómenos del universo, ya los provoquen la mano del hombre o respondan a las leyes generales de la física, no se trata propiamente de creaciones, sino simplemente de transformaciones de la materia. Los únicos elementos que el espíritu humano encuentra, una y otra vez, cuando analiza la idea de la reproducción son los de la combinación y la separación; y lo que ocurre es la reproducción del valor» (se refiere al valor de uso, aunque el mismo Verri, al polemizar aquí contra los fisiócratas no está muy seguro de la clase de valor de que habla) «y de la riqueza, cuando, en los campos, la tierra, el aire, y el agua se convierten en trigo, o también cuando, por la mano del hombre, la secreción de un insecto se convierte en seda o algunas partículas de metal se combinan para formar un reloj de repetición». (Pietro Verri, Meditazioni sulla Economie Politica, [Meditaciones sobre economía política] —obra primeramente impresa en 1771-, en la Colección de Economistas Italianos de Custodi, Parte moderna, t. Xv, págs. $21 \mathrm{s.}$.).

14 Cfr. Hegel, Phiylosophie des Rechts [«Filosofía del derecho»], Berlín 1840, pág. $250 \$ 190$.

15 El lector advertirá que aquí no hablamos del salario o valor que el obrero percibe, supongamos, por una jornada de trabajo, sino del valor de las mercancías en que se objetiva su jornada de trabajo. En esta fase de nuestra exposición aún no existe la categoría de salario.

16 Nota a la 2. ${ }^{\text {a }}$ ed.: Para demostrar «que sólo el trabajo constituye la medida real y definitiva por la que en todo momento puede estimarse y compararse el valor de todas las mercancías», dice A. Smith: «Para el propio trabajador, cantidades iguales de trabajo tienen necesariamente, en cualquier época y en cualquier lugar, el mismo valor. En condiciones normales de salud, fuerza, actividad, y con el grado medio de destreza que hay que suponérsele, tiene siempre que sacrificar la misma porción de su descanso, libertad y dicha» (Wealth of Nations [«Riqueza de las naciones»], lib. I, cap. v). Por una parte, A. Smith confunde aquí (no siempre) la determinación del valor por la cantidad de trabajo invertida en la producción de una mercancía con la determinación de los valores de las mercancías por el valor del trabajo, tratando por tanto de demostrar que cantidades iguales de trabajo tienen siempre el mismo valor. Por otra parte, barrunta que el trabajo, en cuanto se expresa en el valor de las mercancías, rige sólo como gasto de fuerza de trabajo, pero concibiendo este gasto, simplemente como un sacrificio del descanso, la libertad y la dicha, y no también como una realización normal de la vida. Aunque no hay que olvidar que a quien se refiere es precisamente al moderno trabajador asalariado. Es mucho más acertado lo que dice el precursor anónimo de A. Smith citado en la nota 9: «Un hombre ha empleado una semana en producir este objeto necesario... y aquel que quiera ofrecerle algún otro objeto a cambio de él puede estimar más acertadamente cuál es propiamente su equivalente, si calcula qué objeto es el que le ha costado el mismo trabajo (labour) y tiempo. En realidad esto significa intercambiar el trabajo (labour) que un hombre ha empleado en un objeto en determinado tiempo por el trabajo (labour) de otro, empleado durante el mismo tiempo en otro objeto" (Some Thoughts on the Interest of Money in general, etc., pág. 39) - (Adición a la 4. ${ }^{a}$ ed.: La lengua inglesa tiene la ventaja de poseer dos términos distintos para expresar estos aspectos diferentes del trabajo. El trabajo cualitativamente determinado, que crea valores de uso, se llama work, por oposición a labour; el que crea valor y sólo se mide cuantitativamente se llama labour, por oposición a work. V. nota a la traducción inglesa. F.E.).

17 Los pocos economistas que como S. Bailey, se han ocupado del análisis de la forma del valor no han 
podido llegar a ningún resultado, por dos razones: en primer lugar, por que confunden la formas de valor y el valor, y en segundo lugar, porque, bajo la burda influencia del burgués práctico, se fijan de una vez por todas, exclusivamente en la determinación cuantitativa. «El poder de disposición sobre la cantidad... constituye el valor» (Money and its Vicissitudes, [«El dinero y sus vicisitudes»], Londres 1837, pág. 11). Autor, S. Bailey.

17a Nota a la 2. ${ }^{a}$ ed.: Uno de los primeros economistas que después de Willian Petty, advirtió la naturaleza del valor, el famoso Franklin, dice «Como el comercio en general no es otra cosa que el intercambio de un trabajo por otro trabajo, es en trabajo como más acertadamente se estima el valor de las cosas». (The Works of B. Franklin [Obras de B. F.], ed. por Sparks, Boston, 1836 t. II pág. 267). Franklin no es consciente de que, al estimar el valor de todas las cosas «en trabajo», hace abstracción de la diferencia entre los trabajos intercambiados, reduciéndolos así a trabajo humano igual. Pero, aunque no lo sepa, lo dice. Habla primero de un «trabajo», luego «del otro trabajo» y por último del «trabajo» en general, sin calificación alguna, como sustancia del valor de todas las cosas. [En la parte correspondiente a la edición francesa, el texto continúa: De no ser así, tendría que haber dicho: puesto que el intercambio de botas o zapatos por mesas no es más que un intercambio de zapatería por carpintería, ¡es mediante el trabajo del carpintero como se habrá de estimar con mayor exactitud el valor de las botas! Al servirle en general de la palabra «trabajo», se hace abstracción del carácter útil y de la forma concreta de los distintos trabajos]. * En la versión francesa, el pasaje anterior dice: ...De esta manera, las condiciones que es necesario cumplir para expresar el valor del lienzo parecen contradecirse mutuamente. Por un lado, es necesario representarlo como una pura condensación de trabajo humano abstracto, puesto que, en tanto valor, esa es la única realidad que tiene la mercancía. Al mismo tiempo, esta condensación debe revestir la forma de un objeto visiblemente distinto del propio lienzo y que, sin dejar de pertenecer a éste, sea también propio de otra mercancía. Este problema ésta ya resuelto. En efecto, hemos visto que, en cuanto se encuentra como equivalente, la chaqueta ya no tiene necesidad de pasaporte para demostrar su carácter de valor. $\mathrm{Al}$ desempeñar ese papel, su propia forma de existencia se vuelve una forma de existencia del valor;...

$18 \mathrm{Al}$ hombre le ocurre, en cierto modo, lo que a la mercancía. Como no viene al mundo como un espejo —ni en calidad de filósofo fichteano: «Yo soy yo»—, el hombre se reconoce ante todo reflejado en otro hombre. Sólo al relacionarse con el hombre Pablo como igual suyo, el hombre Pedro se relaciona con sigo mismo en cuanto a hombre. De este modo, Pablo rige (gilt) para él. Con pelos y señales, en su paulina corporeidad, como forma de manifestación del genus (género) hombre.

19 La palabra «valor» se usa aquí, como ya antes lo hemos hecho ocasionalmente, para significar el valor cuantitativamente determinado, es decir, la magnitud de valor.

20 Nota a la 2. a ed.: Esta incongruencia entre la magnitud del Valor y su expresión relativa es explotada por la economía vulgar, con su sagacidad acostumbrada. Por ej.: «Reconoced únicamente que a baja porque sube в (lo dado a cambio por A), aunque entre tanto no se invierta en A menos trabajo que en B, y vuestro principio general del valor se vendrá a tierra... Si se concede que, al aumentar el valor de A con relación a B, disminuye relativamente el valor de B, desaparecerá bajo sus pies el fundamento en que Ricardo hace descansar su gran tesis de que el valor de una mercancía se determina siempre por la cantidad de trabajo que en él se contiene; puesto que, si al cambiar los costos de A, no sólo cambia su propio valor en relación con в sino que cambia también el valor de в en relación con A, pese a no mediar cambio alguno en cuanto a la cantidad de trabajo necesario para la producción de B, lo que se viene abajo no es sólo la doctrina según la cual es la cantidad de trabajo invertido en un artículo la que determina su valor, sino también la que sostiene que el valor de un artículo se regula por su costo de producción». (J. Broadhurst, Political Economy [«Economía política»], Londres 1842, págs. 11, 14). El señor Broadhurst pudo haber dicho igualmente: Véase la serie de proporciones 10/20, 10/50, 10/100, etc. El número 10 permanece invariable, a pesar de lo cual su magnitud proporcional, su magnitud en relación con los denominadores 20, 50, 100, etc., va decreciendo constantemente. Se viene a tierra, con ello, el gran principio según el cual la magnitud de un número entero, por ej. 10, se «regula» por el número de veces que en él se contiene la unidad.

** La versión francesa introduce aquí los dos párrafos siguientes, cuyo texto se basa en el del Apéndice 
a la edición de 1867 :

En tanto que valores, todas las mercancías son expresiones iguales de una misma unidad, el trabajo humano, reemplazables unas por otras. Por consiguiente, una mercancía es intercambiable por otra cuando posee una forma que la hace aparecer como valor.

Una mercancía es inmediatamente intercambiable por toda otra mercancía de la que ella sea el equivalente, es decir: el lugar que ella ocupa en la relación de valor hace de su forma natural la forma valor de la otra mercancía. No necesita adoptar una forma diferente de su forma natural para manifestarse como valor ante la otra mercancía, para tener vigencia como valor y, por tanto, para ser intercambiable por ella. La forma de equivalente es, pues, para una mercancía, la forma bajo la cual ella es inmediatamente intercambiable por otra. Cfr. La forma valor. I, 3, a), en: C. Marx y F. Engels, Escritos económicos varios, México, 1962.

*** La versión francesa continúa: ...Pero una mercancía, bajo la forma de equivalente, figura como simple cantidad de una materia cualquiera precisamente porque la magnitud de su valor no ésta siendo expresada. Las contradicciones que encierra la forma de equivalencia exigen ahora un examen más detenido de sus peculiaridades.

21 Con estas determinaciones de reflexión recíproca ocurre algo muy particular. Tal hombre, por ej., sólo es rey porque otros hombres se comportan hacia él como súbditos. A la inversa, éstos creen que son súbditos porque él es rey.

22 Nota a la 2. ${ }^{\text {a }}$ ed.: F. L. A. Ferrier (Sous-inspecteur des douanes [Subinspector de aduanas]), Du Gouvernement consideré dans ses rapports avec le commerce, [ «Sobre el gobierno considerado en sus relaciones con el comercio»], París 1805, y Charles Ganilh, Des Systemes D’Economie Politique, etc. [«Sobre los sistemas de economía política, etc.»] 2. ${ }^{\text {a }}$ ed., París, 1821.

**** La edición francesa introduce aquí abriendo un nuevo párrafo, esta frase: «El producto del trabajo adquiere la forma mercancía cuando su valor adquiere una forma de manifestación, el valor de cambio, opuesta a su forma natural; por consiguiente, cuando él mismo es concebido como la unidad en la que se fundan estos contrastes...».

22a Nota a la 2. ${ }^{\text {a }}$ ed.: En Homero, por ej., el valor de una cosa es expresado en una serie de cosas distintas. 23 Por eso se habla de lo que el lienzo vale en chaquetas, cuando su valor se expresa en chaquetas, de su valor en trigo, cuando se expresa en trigo, etc. Cada una de estas expresiones indica que es un valor el que se expresa en los valores de uso chaqueta, trigo, etc. «Como el valor de toda mercancía indica la proporción de ésta en el intercambio, podemos designarlo como valor en trigo, en paño, etc., según la mercancía con que ella se compare; por eso hay mil clases distintas de valores, tantos como mercancías existen y todos ellos son valores igualmente reales que nominales». (A Critical Dissertation on the Nature, Measures, and Causes of Value: chiefly in reference tothe writings of Mr. Ricardo and his followers. By the author of Essays on the Formation etc. of Opinions. [ «Disertación crítica sobre la naturaleza, medidas y causas del valor; con referencia principalmente a las obras del Sr. Ricardo y sus seguidores, por el autor de ensayos sobre la formación etc. de opiniones»], Londres 1825, pág. 39). S. Bailey, autor de esta obra anónima, que en su día hizo mucho ruido en Inglaterra, cree haber destruido toda determinación conceptual del valor con esta referencia a las abigarradas expresiones relativas del mismo valor de una mercancía. Es innegable, por lo demás, que, a pesar de su propia limitación, localizó y puso el dedo en ciertas llagas de la teoría ricardiana; esto quedó demostrado, por la irritación con la que la escuela de Ricardo lo atacó, por ejemplo en la «Westminster Review».

24 En realidad, no es perceptible, en la forma de la intercambiabilidad general directa, el que ella sea una forma de la mercancía que siendo antagónica de la forma de su intercambiabilidad indirecta, es tan inseparable de ella como el carácter positivo de un polo magnético lo es del carácter negativo del otro. Cabe, por tanto, la ilusión de que es posible imprimir a todas las mercancías al mismo tiempo el cuño de la intercambiabilidad directa, como cabe también la ilusión de que todos los católicos pueden estar en funciones de Papa. Para el pequeño burgués que ve en la producción de mercantil el nec plus ultra [la realización insuperable] de la libertad humana y de la independencia del individuo, sería muy deseable, naturalmente, verse a salvo de los inconvenientes que esta forma lleva aparejados, principalmente el de 
la no intercambiabilidad directa de las mercancías. La pintura de esta utopía de filisteo nos la ofrece el socialismo proudhoniano, que, como ya hube de señalar yo en otro lugar, no presenta siquiera el mérito de la originalidad, pues fue desarrollado mucho antes que él, y bastante mejor, por Gray, Bray y otros. Lo que no impide que, en ciertos círculos, semejante sabiduría se extendía bajo el nombre de «sciencie». Jamás una escuela ha empleado tan atroche y moche la palabra «sciencie» como la de Proudhon, por aquello de que: «Donde faltan conceptos, se instala oportunamente una palabra».

$* * * * *$ En el original: [...] a la forma de dinero [Zur Geldform].

$* * * * * \star$ En el original: D) La forma de dinero [D) Geldform].

25 Recuérdese que China y las masas rompieron a bailar cuanto todo el mundo parecía haberse detenido... Pour encourager les autres [Para animar a los otros].

26 Nota a la 2. ${ }^{\text {a }}$ ed.: Los antiguos germanos calculaban la extensión de una yugada de tierra tomando como base el trabajo de un día, razón por la cual la yugada se llamaba Tagwerk (o Tagwanne) [obra de un día], (en latín: jurnale o jurnalis, terra jurnalis, jornalis o diurnalis [tierra diaria], Mannwerk [trabajo de un hombre], Mannskraft [fuerza de un hombre], Mannsmaad, Mannshauet, etc. V. Georg Ludwing von Maurer, Einleitung zur Geschichte der Mark Hof, usw Verfassung [«Introducción a la historia de la organización de la Marca, alquería, etc.»], Munich, 1854, pág. 129 ss.

27 Nota a la $2^{a}$ ed.: Por tanto, cuando Galiani dice que el valor es una relación entre personas - «La richezza é una ragione tra due persone»-, habría debido añadir: una relación oculta en una envoltura cósica. (Galiani, Della Moneta, p. 21, t. III de la colección Custodi de Scrittori Classici Italiani di Economia Politica, parte moderna, Milán, 1803).

28 «Qué pensar de una ley que sólo puede inponerse mediante revoluciones periódicas? Se trata precisamente de una ley natural basada en la inconsciencia de los interesados». (Friedrich Engels, Umrisse $z u$ einer Kritik der Nationalökonomie [«Esbozo de una crítica de la economía política»], en DeutschFranzösische Jahrbücher («Anales Franco-Alemanes»), dirig. Por Anrnold Ruge y C. Marx, París, 1844). 29 Nota a la 2. ${ }^{\text {a }}$ ed.: Tampoco a Ricardo le falta su robinsonada. «Al pescador y al cazador primitivos los hace aparecer ya desde el primer momento como poseedores de mercancías, que intercambian sus piezas cazadas y pescadas con arreglo al tiempo de trabajo objetivado en estos valores de cambio. Con esta oportunidad, Ricardo cae en el anacronismo de presentar al pescador y cazador primitivos aplicando, para calcular el costo de sus instrumentos de trabajo, las tablas de anualidades vigentes en 1817 en la Bolsa de Londres. Fuera de la sociedad burguesa la única forma de sociedad que Ricardo parece conocer son los «paralelogramos» del señor Owen. (C. Marx, Zur Kritik etc. [«Contribución a la crítica, etc.»], pág. $38 \mathrm{~s}$.).

30 Nota la 2. ${ }^{\text {a }}$ ed.: «Es un prejuicio ridículo, que se ha extendido en estos últimos tiempos, el creer que la forma de la propiedad común naturalmente dada es específicamente eslava e incluso exclusivamente rusa. Es, en realidad, la forma primitiva cuya existencia puede demostrarse entre los romanos, los germanos y los celtas, y de la que seguimos encontrando todo un mapa modelo con numerosos testimonios, aunque parcialmente ya en ruinas, entre los hindúes. Un estudio preciso de las formas asiáticas, especialmente hindúes, de propiedad común pondrían de manifiesto cómo las diferentes formas de la propiedad común naturalmente dada conducen a diferentes formas de disolución de este régimen. Por ej., los diversos tipos originales de propiedad privada romana y germánica son derivables de las diferentes formas de la propiedad común de la India». (C. Marx, Zur Kritik, etc., pág. 10).

31 En los libros tercero y cuarto de esta obra tendremos ocasión de ver en qué consiste la limitación [das Unzulängliche] del mejor de los análisis de la magnitud del valor, el de Ricardo. Por lo que se refiere al valor en general, la economía política clásica nunca distingue expresamente y con clara conciencia el trabajo, en cuanto se expresa en el valor, del mismo trabajo expresado en el valor de uso del producto. No queremos decir, naturalmente, que no registre de hecho la diferencia, puesto que considera al trabajo, en un caso, cuantitativamente y, en otro, cualitativamente. Pero no llega a ocurrírsele que la diferencia puramente cuantitativa entre los trabajos presupone su igualdad o unidad cualitativa y, por tanto, la reducción de todos ellos a trabajo humano abstracto. Ricardo, por ej., se manifiesta de acuerdo con Destutt de Tracy, cuando éste dice: «Puesto que es evidente que nuestra única riqueza originaria son nuestras 
dotes físicas y espirituales, el empleo de estas, es decir, un cierto tipo de trabajo, constituye nuestro tesoro originario; es el empleo de estas dotas el que crea todas las cosas a que damos el nombre de riqueza... Es evidente, además que todas estas cosas representan solamente el trabajo que las ha creado, y si tienen un valor, o incluso dos valores distintos, lo deben solamente al (valor) «del trabajo del que nacen». (Ricardo, The principles of Pol Econ., [«Los principios de la economía política»] 3. ${ }^{a}$ edición, Londres 1821, pág. 334) (Cfr. Destutt de Tracy, Elements d'ideologie [«Elementos de Ideología»], partes Iv y v, París 1826 , págs. $35 \mathrm{~s}$ ). Nos limitamos a indicar que Ricardo atribuye a Destutt el sentido, más profundo, que él da a las palabras de éste. Es cierto que Destutt dice por una parte que todas las cosas que forman la riqueza «representan el trabajo que las ha creado», pero dice también, por otro, que sus «dos valores distintos» (el valor de uso y el valor de cambio) los deben al «valor del trabajo». Cae con ello en la simpleza de la economía vulgar que da por supuesto el valor de una mercancía (aquí del trabajo) para determinar luego, sirviéndose de él, el valor de las demás. Ricardo lee a Destutt como si éste dijera que tanto en el valor de uso como en el valor de cambio se contienen trabajo (no valor del trabajo). Pero él mismo se halla tan ajeno al análisis del carácter dual del trabajo - que se halla representado doblemente-, que en todo el capítulo de su obra titulada «Value and Riches, their Distinctive Porporties» [«Valor y riqueza; sus propiedades distintivas»], tiene que debatirse trabajosamente con las trivialidades de un J. B. Say. De ahí que, al final, se manifieste asombrado ante el hecho de que Destutt coincida con él acerca del trabajo como fuente del valor, mientras, por otra parte, coincide con Say en lo que se refiere al concepto de valor. 32 Una de las deficiencias fundamentales de la economía política clásica es que no logró nunca extraer del análisis de la mercancía, y especialmente del valor de ésta, la forma valor, que es precisamente la que lo constituye como valor de cambio. Precisamente en la persona de sus mejores representantes, A. Smith y Ricardo, trata la forma-valor como algo perfectamente indiferente o exterior a la naturaleza misma de la mercancía. La razón de ello no está solamente en que su atención se ve totalmente absorbida por el análisis de la magnitud del valor. Es más profunda. La forma-valor del producto del trabajo constituye la forma más abstracta pero también la más general del modo de producción burgués; caracteriza a éste como un tipo particular de producción social y, con ello, al mismo tiempo, en su determinación histórica. Por ello, si equivocadamente se ve (versieht) en ella la forma natural y eterna de la producción social, se pasa también por alto (übersieht), necesariamente, lo que hay de específico en la forma-valor $y$, por tanto, en la forma-mercancía y en esta forma misma pero desarrollada hasta llegar a la formadinero, a la forma-capital, etc. De ahí que en economistas coinciden por entero acerca del tiempo de trabajo como medida de la magnitud del valor, nos encontramos con las más variadas y contradictorias ideas acerca del dinero, es decir, de la figura definitiva del equivalente general. Ello resalta con toda intensidad, por ej., en el modo de tratar el sistema bancario, donde ya no sirve de nada las definiciones del dinero basadas en lugares comunes. Así es como, en contraposición a ellos, ha surgido un sistema mercantilista restaurado (Ganilh, etc.) que ve en el valor sólo la forma social o mejor dicho, sólo la apariencia, carente de sustancia, de esa forma. Para señalarlo de una vez por todas, diré que entiendo por economía política clásica toda la que, desde W. Petty, investiga la interde interdependencia interna de las relaciones burguesas de producción, por oposición a la economía vulgar, que implemente vaga dentro de la interdependencia aparente, rumiando incansablemente el material suministrado mucho tiempo atrás por la economía científica, a fin de encontrar una explicación plausible a los fenómenos más toscos, y para satisfacer las necesidades domesticas de la burguesía, limitándose, por lo demás, a sistematizar, pedantizar y proclamar como verdades eternas las ideas banales y autocomplacientes que los agentes burgueses de la producción se forman acerca de su mundo, considerado por ellos como el mejor de los mundos posibles.

33 «Los economistas tienen una manera muy curiosa de proceder. Para ellos, hay dos clases de instituciones, las naturales y las artificiales. Las instituciones del feudalismo son instituciones artificiales, las de la burguesía naturales. Se asemejan en esto a los teólogos, que distinguen también dos clases de religiones. Toda la religión que no sea la suya propia es una invención de los hombres; en cambio la suya es una revelación de Dios. Según esto, ha habido una historia, pero ya no la hay». (C. Marx, Misère de la Philosophie, Réponse à la Philosophie de la Misère par M. Proudhon, [«Miseria de la Filosofía. 
Respuesta a la filosofía de la miseria por el Sr. Proudhon»] 1847, pág. 113). Es verdaderamente chusco el señor Bastiat, cuando se imagina que los griegos y los romanos sólo vivían del botín. Para poder vivir del botín durante varios siglos, tiene sin embargo que haber algo que saquear o aquello que se saquea tienen que reproducirse constantemente. Parece, pues, que también los griegos y los romanos tenían un proceso de producción, es decir, una economía, que constituía la base material de su mundo, ni más ni menos que la economía burguesa constituye la del mundo actual. ¿ $\mathrm{O}$ acaso cree el señor Bastiat que un modo de producción basado en el trabajo de los esclavos tiene por base un sistema de rapiña? Si así lo hiciera, se colocaría en un terreno peligroso. Si hasta un gigante del pensamiento como Aristóteles podía equivocarse en la apreciación del trabajo de los esclavos, ¿̨por qué ha de acertar en sus juicios sobre el trabajo asalariado un economista enano como Bastiat? Aprovecho la ocasión para salir brevemente al paso de una objeción que me fue formulada por un periódico alemán de los Estados Unidos, al publicarse mi obra Contribución a la crítica de la economía política, en 1859. Decía el crítico que mi concepción según la cual el modo de producción determinado y las relaciones de producción que a él corresponde en cada caso, en una palabra, «la estructura económica de la sociedad, compone la base real sobre la que se erige una supraestructura jurídica y política a la que corresponden determinadas formas sociales de conciencia», según la cual «el modo de producción de la vida material condiciona en general el proceso de la vida social, política y espiritual», que todo esto era sin duda exacto aplicado al mundo actual, en el que imperan los intereses materiales, pero no con respecto a la Edad Media, cuando dominaba el catolicismo, ni a Atenas y Roma, donde mandaba la política. Es extraño, ante todo, que a alguien se le ocurra dar por supuesto que puede haber nadie a quien no le sean familiares estos manidos tópicos sobre la Edad Media y el mundo antiguo. Si hay algo claro es que ni la Edad Media podía vivir del catolicismo ni la Antigüedad de la política. Es, por el contrario, el modo cómo ganaban su vida el que explicaba por qué el papel principal lo desempeñaba en este caso la política y en otro el catolicismo. Dicho sea de paso, no hace falta estar muy versado, por ej., en la historia de la República romana para saber que su historia secreta es la historia de la propiedad de la tierra. Por lo demás, ya don Quijote debió pagar caro su error de creer que la caballería andante era compatible con todas las formas económicas de la sociedad.

34 "Value is a property of things, riches of man. Value, in this sense, necessarily implies exchanges, riches do not». (Observations on some verbal disputes in Pol. Econ., particularly relating to the value and to supply and demand. [«Observaciones sobre algunas disputas verbales sobre econ. pol., especialmente relacionadas con el valor y la oferta y la demanda»], Londres 1821, pág. 16).

35 "Riches are the attribute of man, value is the attibute of commodities. A man or a community is rich, a pearl or a diamond is valuable... A pearl or a diamond is valueble as a pearl or diamond». (S. Bailey, I.c., págs. 165 ss.).

$36 \mathrm{El}$ autor de las observations y S. Bailey culpan a Ricardo de convertir el valor de cambio, de algo puramente relativo, en algo absoluto. Todo lo contrario. Ricardo reduce la aparente relatividad que estas cosas, por ej., el diamante o la perla, poseen en cuanto valores de cambio a la verdadera relación que se oculta tras la apariencia, a su relatividad como meras expresiones del trabajo humano. Si los ricardianos contestaron a Bailey de un modo violento, pero no conveniente, ello se debió sencillamente, a que no encontraban en el propio Ricardo ninguna luz acerca de la interdependencia interna que existe entre el valor y la forma del valor, o sea el valor de cambio. 